\title{
Demografia do consumo urbano: um estudo sobre a geração de resíduos sólidos domiciliares no município de Belo Horizonte*
}

\author{
Harley Silva ${ }^{\star \star}$ \\ Alisson Flávio Barbieri ${ }^{\star * \star}$ \\ Roberto L. Monte-Mór ${ }^{\star \star \star \star}$
}

\begin{abstract}
Este trabalho explora relações entre fatores socioeconômicos e demográficos e a produção de resíduos sólidos domiciliares - o lixo doméstico -, para o município de Belo Horizonte em 2002. A proposta foi investigar se diferenciais socioeconômicos (especificamente renda e educação) e demográficos (especificamente estrutura etária e domiciliar) são importantes na definição do volume de resíduos gerado em sub-regiões do município. O consumo, nesse sentido, é visto como o elo entre as dimensões "população" e "geração de resíduos". A fonte de dados sobre a geração de resíduos sólidos é a Superintendência de Limpeza Urbana (SLU), responsável pela coleta e sistematização das informações em uma malha cartográfica digital. Tal representação espacial das informações permitiu concatená-las com os dados da malha digital das Áreas de Ponderação do Instituto Brasileiro de Geografia e Estatística (IBGE), referentes ao Censo Demográfico 2000. Métodos estatísticos multivariados foram empregados para investigar as associações entre variáveis populacionais e a produção de resíduos. O trabalho se destaca no cenário dos estudos de população no Brasil pelo uso inédito de informações produzidas sobre resíduos sólidos urbanos e a interação de sua produção com aspectos socioeconômicos e demográficos. Os resultados indicam que a concentração de domicílios unipessoais, população e chefes com 60 anos e mais, e idade média elevada, algo como um "perfil demográfico urbano-contemporâneo", surge recorrentemente como aspecto demográfico central na diferenciação de áreas de maior geração per capita. Estes fatores são associados constantemente à renda e escolaridade elevadas.
\end{abstract}

Palavras-chave: População. Meio ambiente. Consumo. Resíduos sólidos urbanos.

\footnotetext{
* Agradecemos à Capes pelo financiamento - via bolsa de manutenção - durante o mestrado do primeiro autor no Cedeplar-UFMG, bem como à Superintendia de Limpeza Urbana - SLU e à Secretaria Municipal de Fazenda - SMF da Prefeitura de Belo Horizonte pela gentil cessão de dados de geração de RSU e tributação utilizados nesse trabalho.

** Economista e mestre em Demografia pela Universidade Federal de Minas Gerais (UFMG). Secretaria Estadual de Desenvolvimento Regional e Política Urbana de Minas Gerais (harley74@gmail.com).

${ }^{* \star *}$ Professor do Departamento de Demografia e pesquisador do Centro de Desenvolvimento e Planejamento Regional (Cedeplar), Universidade Federal de Minas Gerais (UFMG) (barbieri@cedeplar.ufmg.br).

${ }^{\star \star \star \star}$ Professor e pesquisador do Centro de Desenvolvimento e Planejamento Regional (Cedeplar), Universidade Federal de Minas Gerais (UFMG) (montemor@cedeplar.ufmg.br).
} 


\section{Introdução}

A proposta deste artigo é investigar se diferenciais socioeconômicos, demográficos e espaciais (intraurbanos) são importantes na definição da quantidade e composição dos resíduos - o lixo doméstico - gerados em sub-regiões do município de Belo Horizonte em 2002. A contribuição teórica deste estudo parte de uma visão da relação entre população e ambiente urbano como sendo mediada por um padrão de consumo desigual, com consequentes impactos ambientais diferenciados, em termos da geração de resíduos sólidos domiciliares. $A$ contribuição empírica e metodológica parte da aplicação de técnicas multivariadas de associação entre variáveis socioeconômicas, demográficas e espaciais e a geração de resíduos sólidos, em uma escala intraurbana de análise.

A gestão de resíduos sólidos urbanos (RSUs) é uma das muitas questões ambientais prementes do mundo contemporâneo. Uma das faces deste problema são os resíduos sólidos domiciliares. Sua especificidade é a maneira corriqueira e constante com que cada indivíduo, família e domicílio contribuem a cada instante para a produção de resíduos, rejeitos, lixo doméstico, que de embaraço no espaço domiciliar se transmuta por vezes em transtorno público, crise e até calamidade urbano-ambiental.

As conexões entre população e produção de resíduos não têm certamente sido negadas. No entanto, os estudos populacionais não têm lhes dado a devida atenção. A população aparece usualmente nos estudos a respeito dos determinantes da produção de RSUs, sem outra influência que não de seu tamanho e taxa de crescimento, em geral numa relação que deve ser linear, embora nem mesmo isso seja alvo de discussão mais detalhada (BARBOSA, 2004; COSTA et al., 2005). Ora, atravessamos um momento de mudança demográfica nas sociedades contemporâneas, em geral, e na brasileira, em particular. Buscar a influência da população em processos sociais e ambientais em sentido amplo requer maior atenção às mudanças em curso, não apenas no que tange ao tamanho e ritmo de crescimento populacional, mas também quanto às mudanças em sua estrutura e composição.

A hipótese de trabalho é que diferenciais socioeconômicos e demográficos, especificamente na estrutura etária, tamanho e arranjo e ciclo de vida domiciliar, aliados aos diferenciais de renda e escolaridade, se expressam em um padrão espacialmente diferenciado de geração de resíduos per capita e também de composição do resíduo gerado, especialmente por via de uma relação entre as curvas de consumo e idade.

\section{População, consumo e geração de resíduos sólidos urbanos}

Há uma cadeia complexa de efeitos entre mudança demográfica e alterações no espaço e no ambiente, ambos socialmente construídos. Neste trabalho, nos limitaremos a analisar a relação entre mudanças (ou diferenciais) demográficas, consumo e geração de resíduos. Populações que atravessam mudanças demográficas tendem a viver alterações de quantidade e qualidade dos bens demandados e consumidos (SAWYER, 2002). Alterando-se a quantidade e qualidade dos bens consumidos, altera-se também o padrão de geração de resíduos pela população em geral e por cada domicílio em particular.

A relação entre população e ambiente tem sido objeto de reflexão, pelo menos de forma mais sistemática, desde o trabalho de Thomas R. Malthus na passagem do séc. XVIII para o XIX. Entretanto, o "problema populacional" foi e continua a ser citado de forma frequente, dentro e fora da academia, como sendo predominantemente uma questão de tamanho e taxa de crescimento da população. Esse vem a ser, entretanto, pelo menos um equívoco relativo, em função do caráter dinâmico da população. Diversas características de uma sociedade são afetadas pela dinâmica demográfica, isto é, em função das maneiras por meio das quais a população se altera não apenas em tamanho absoluto, mas também em outros aspectos, como estrutura etária, distribuição espacial e estrutura domiciliar.

Os estudos populacionais denominam de teoria da transição demográfica o cor- 
po teórico que lida com as mudanças de largo espectro nos regimes demográficos. Caldwell (1976) atribui o pioneirismo da moderna teoria da transição demográfica a Frank Notestein. No cenário de divergências que compõem esse campo de estudos, essa é uma das poucas concordâncias. $O$ trabalho de Notestein é a referência inicial da discussão, como atestam Easterlin e Crimmins (1985), Pollak e Watkins (1993) ou Mason (1997): esses e outros autores de diferentes escolas partem de Notestein, mesmo que the atribuindo limitações.

Notestein (1953), ou a teoria clássica da transição de fecundidade, representa o esforço pioneiro para interpretar as transformações demográficas no Ocidente. $O$ autor atribui as mudanças às transformações sociais pela industrialização e urbanização que emergem nas sociedades ocidentais, induzindo, em primeiro lugar, o declínio da elevada mortalidade pré-transição, fator que aumentaria a sobrevivência infanto-juvenil, e, em segundo, abrindo caminho para que famílias não se impusessem uma alta fecundidade como fator de equilíbrio para a conservação dos grupos sociais, como é característico nas sociedades em que a demanda por braços para o trabalho é intensa.

A ascensão e difusão da sociedade urbano-industrial, seu novo perfil de demanda por trabalho, entre outros aspectos, provocaram a desorganização do arranjo sociocultural que moldava o comportamento reprodutivo à necessidade de alta fecundidade: doutrinas religiosas; códigos morais; leis; hábitos de casamento; organização familiar e educação, entre outros, todos ajustados para manter a alta fecundidade. Porém, em contraste com a queda rápida da mortalidade, a fecundidade (ou seus determinantes sociais) diminuiu (diminuíram) gradualmente e somente em resposta a estímulos fortes de modernização e mudança social, diferentemente do impacto relativamente mais rápido e difuso das novas condições socioambientais-espaciais sobre a mortalidade. Novos padrões de comportamento emergiram capitaneados por um arranjo societal laico, com destaque para instituições modernas como a escola e a firma capitalista, onde prevalecem critérios de racionalidade e cálculo que se impõem ao comportamento reprodutivo (NOTESTEIN, 1953). Todo esse conjunto de mudanças teve um papel central na configuração das sociedades modernas, desde a revolução industrial europeia dos séculos XVIII e XIX, até a sua difusão tardia com o capitalismo e das relações sociais urbano-industriais, nos países periféricos ao longo do século $X X$, e tem sido denominado como a primeira transição demográfica (first demographic transition - FDT).

As décadas recentes, especialmente desde os anos 1960, têm presenciado um novo conjunto de mudanças que também tiveram seus primeiros registros sistemáticos nos países centrais, mas que avançam com nuances próprias em direção às demais áreas do mundo contemporâneo. A maior parte destas transformações relaciona-se às características que anunciam sociedades de arranjo pós-moderno ou pós-industrial: ${ }^{1}$

The transformation of household structure in postindustrial countries has been related to a broad set of population dynamics, which are often summarized under the common umbrella of the second demographic transition (BUZAR; OGDEN; HALL, 2005).

O termo second demographic transition (SDT) é usado como rótulo para mudanças no padrão de união conjugal, comportamento reprodutivo, formação, dissolução e reconstituição de famílias durante a segunda metade do século XX. As principais transformações provêm do adiamento (ou não experimentação) do casamento e da maternidade (paternidade), da multiplicação do número de domicílios unipessoais, uniparentais, arranjos domiciliares não ligados a relações de parentesco, do prolongamento da permanência na casa paterna, das formas alternativas de convivência marital informal

\footnotetext{
${ }^{1}$ As expressões não são equivalentes, embora sejam, às vezes, empregadas como tal. O debate é mais que semântico e gira em torno do grau de perda de centralidade da indústria como um elemento formador das relações socioespaciais nas sociedades contemporâneas, as quais viveram o declínio do chamado pacto Fordista, daí o emprego da expressão pós-fordismo como outro equivalente para o termo pós-industrial. Para detalhes, ver Soja (2000), especialmente capítulo 6.
} 
(coabitação) e procriação dentro destas relações, além do aumento do número de divórcios, dissoluções e recriações de famílias em novos arranjos (LESTHAEGHE, 1995). Tudo concorre para perda de centralidade da família nuclear tradicional, forma de sociabilidade burguesa básica no Ocidente nos últimos 200 anos (BUZAR; OGDEN; HALL, 2005). É também momento de novo declínio acentuado da fecundidade, que, em muitos países, chega abaixo do nível de reposição ${ }^{2}$ e mesmo a uma taxa de fecundidade total $^{3}$ (TFT) de 1,4 filho por mulher, nível inimaginável na primeira metade do século $X X$.

Lesthaeghe (1995) identifica dois conjuntos de motivação para a queda da fecundidade na modernidade. $\mathrm{O}$ primeiro, marcado pelo investimento paterno em child quality, adequado à transição de fecundidade (FDT) do século XIX até início do XX, corresponde à penetração dos ideais de vida burguesa, a carreira aberta ao talento (HOBSBAWM, 2004). A esfera doméstica torna-se o lugar das preocupações com a qualidade da educação familiar, com o pai e a mãe assumindo papéis de grande assimetria. O segundo momento (SDT), a partir dos anos 1960, marca o declínio da era child-king (ÁRIES, 1980 apud LESTHAEGHE, 1995), em que ascendem preocupações centradas no adulto, ideais de realização pessoal e valorização das relações mais igualitárias entre cônjuges, função da emancipação feminina via educação, mercado de trabalho e controle sobre o comportamento reprodutivo. Filhos ainda são importantes, mas não mais o topo das preocupações do casal. Aí figuram agora preocupações de autorrealização.

Fora do âmbito das relações homem-mulher, a autonomia do indivíduo em relação às instituições avançou por avenidas largas na segunda metade do século $X X$, refletindo-se nos arranjos familiares e no comportamento reprodutivo. A coabitação veio a ser um novo rito de passagem para a protest generation, embora não mais que uma expressão de autonomia para aqueles a quem chegava por difusão. "Libertos" da família como instituição organizadora da sociedade, os indivíduos encontram novas e fluidas formas de associação pessoal. Múltiplos tipos de arranjos domiciliares surgem, ditados ou não por formalidades legais ou religiosas, laços de parentesco e sangue. Além disso, ao longo da vida (que ganhou mais e mais em extensão desde a FDT), os indivíduos passam por vários tipos de arranjos, alguns conscientemente provisórios (repúblicas estudantis, moradias transitórias), outros nem tanto (casamentos e uniões instáveis, residência com pais ou parentes por dissolução do núcleo familiar, vida de solteiro com amigos, casamentos part-time, famílias pluri-residenciais, casais living apart together, mudanças de opção sexual, entre outras). Assim, mudanças de atitude a respeito da formação, dissolução e natureza das relações permanecem no coração das transformações familiares, domésticas e demográficas (BUZAR; OGDEN; HALL 2005).

Finalmente, na medida em que a intenção é perseguir o intercâmbio entre mudanças demográficas, consumo e pressão ambiental via geração de resíduos sólidos urbanos, podemos afirmar com Buzar, Ogden e Hall (2005, p. 422) que:

the societal effects of SDT extend far beyond the conventional domains of population trends. The destabilization of traditional family structure can be connected to a much wider range of social processes.

\section{Mudanças demográficas e comportamento do consumo}

Neste contexto de mudanças, a unidade domiciliar ganha notoriedade como agente de transformação, expressão de tendências e unidade de análise (LOREK, 2004). Há descompasso entre taxas de crescimento

\footnotetext{
2 Comportamento reprodutivo que teoricamente asseguraria a reposição perfeita de uma população com crescimento nulo. Convenciona-se que seria atingido se fosse alcançada uma TFT (vide nota seguinte) igual a 2,1 filhos por mulher (CARVALHO et al., 1998).

${ }^{3}$ Medida demográfica que expressa o número médio de filhos que uma mulher teria, ao longo de seu período reprodutivo (15 a 49 anos), caso convivesse, em todo o período, com um comportamento reprodutivo inalterado. Esta mulher é por isso dita "hipotética" (CARVALHO et al., 1998).
} 
das populações, que tendem a diminuir com a baixa fecundidade, e o ritmo rápido de formação ou dissolução dos próprios domicílios. Declina o tamanho médio dos domicílios e se multiplicam aqueles unipessoais (MEDEIROS; OSÓRIO, 2002; ALVES, 2004). Assim, a defasagem entre as taxas de crescimento do número de domicílios e da população em geral é um aspecto importante das novas tendências demográficas, cujas consequências são relevantes para a produção do espaço urbano - via demanda por moradia por exemplo -, assim como para os impactos ambientais da população (BUZAR; OGDEN; HALL, 2005). Sassen (1991 apud BUZAR; OGDEN; HALL, 2005) destaca que o domicílio é a unidade-chave do consumo nas sociedades atuais. $O$ crescimento do número de domicílios, especialmente os pequenos, leva a transformações fundamentais na estrutura do consumo. A multiplicação da oferta de serviços residenciais que se assiste nos centros urbanos atuais é apenas um dos aspectos desta realidade.

Acrescente-se que os domicílios característicos da SDT se notabilizam pelo padrão de consumo orientado para o mercado. Mesmo que a renda persista como questão-chave para o consumo e que a SDT não ocorra apenas entre os ricos, domicílios onde não há papéis de gênero tradicionais definidos, onde os indivíduos permanecem fora todo o dia e onde predominam adultos tendem a consumir mais produtos oferecidos como ágeis e práticos, adequados à "corrida" vida urbana. Estes fatores, conjugados ao poder de criação de necessidades da propaganda e do marketing, criam um quadro ideal ao sobreconsumo ou consumo pessoal com potencial ambiental negativo (misconsumption) (PRINCEN, 1999). Na dinâmica do domicílio contemporâneo, em que inclusive crianças e adolescentes são bombardeados pelas exigências éticas do consumo:

In their entirety, the demographic, cultural and economic outcomes [...] constitute a powerful force of urban transformation. This is because cities simultaneously shape, and are shaped by, the consumption practices and mobility pattern of their constituent households. [...] [Your] urban agency [...] embodies the joint spatial outcomes of a myriad social change that have been unfolding during the past few decades, including the SDT, the new positionality of genders and families structures [...] and post-Fordist restructuring (BUZAR; OGDEN; HALL 2005, p. 425-426)

Agentes demográficos, econômicos e socioespaciais, os domicílios são um vetor na produção do espaço. Sua distribuição no tecido urbano se distingue por graus de segregação (BUZAR; OGDEN; HALL, 2005). Dentro de uma mesma cidade constituem-se circuitos que convivem à distância, não se misturam, têm articulações econômicas e sociais diferenciadas (SANTOS, 2004). O processo aparece na segregação das áreas pobres das cidades - as favelas -, mas também nos condomínios (horizontais e verticais), fechados e vigiados; na diferenciação dos bairros de classe média, seus condomínios verticais e espaços públicos rarefeitos (MARQUES, 2005). Refletem o agrupamento em certas regiões da cidade de domicílios com traços comuns, que vão do tamanho e composição ao padrão de renda, educação e consumo:

Aprofunda-se o movimento de auto-segregação das elites e aumenta a distância social entre essas categorias e os trabalhadores em geral, cristalizada na forma de contínuo movimento de periferização dos segmentos operários e populares. Ao mesmo tempo, as classes médias vão se espraiando pelo território [das cidades], aproximando, em um dos extremos dos grupos operários e no outro das categorias dirigentes (MENDONÇA; GODINHO, 2003).

\section{Domicílios, estrutura etária e consumo}

Não constitui algo novo o fato de que a estrutura etária das populações exerce efeitos importantes sobre o comportamento de variáveis econômicas e sociais (PRESTON, 1987; LAM, 1997, 2006). O que não é lugar comum, embora também não seja novidade, é que os estudos em população e meio ambiente façam uso da evidência conhecida de que a estrutura etária da população tem efeitos sobre as questões ambientais via padrão de consumo por idade.

A hipótese implícita é que o padrão de consumo dos indivíduos e das famílias é influenciado por sua estrutura etária. Em 
diferentes etapas de seu ciclo de vida, os indivíduos têm diferentes necessidades e preferências, variando, portanto, seu consumo. ${ }^{4} \mathrm{~A}$ maior ou menor participação percentual de pessoas em tal ou qual grupo etário de uma população terá impacto sobre a curva de consumo agregado por idade. Além disso, como o consumo é, entre outros fatores, uma função da renda pessoal ou domiciliar, esta, por sua vez, não é indiferente à estrutura etária, havendo o impacto deste efeito de composição. Tudo isso permite falar em uma curva idade-consumo que é sensível às variáveis demográficas (QUEIROZ et al., 2006).

O consumo, obviamente, afeta o ambiente. Recursos são retirados da natureza em larga escala para fornecer alimento, energia ou matéria-prima para populações humanas. Este efeito pode ser negativo, por exemplo, quando subprodutos perigosos são gerados durante a produção ou consumo; também pode sê-lo pela deposição de resíduos decorrentes do processo de consumo. Um exemplo hipotético é a produção de um carro, que requer o emprego de matérias-primas diversas e gera resíduos sólidos, líquidos e gasosos. Uma vez em mãos dos usuários, carros consomem combustíveis fósseis, liberando poluentes na atmosfera, além de seu uso gerar outros tipos de resíduos: óleos, fluidos, pneus, baterias, peças que se desgastam e precisam ser repostas. O próprio carro, afinal, deve ser descartado (ou reciclado) se e quando sua vida útil chega ao fim. Esse processo de produção e consumo interage com fatores demográficos, influenciando-o direta ou indiretamente: o envelhecimento ou rejuvenescimento da população; os modelos de formação de domicilio; a situação de chefia por idade, gênero e raça; entre outros (PEBLEY, 1998).

O padrão de formação de famílias e domicílios tem efeitos sobre o consumo e por consequência sobre o meio ambiente.
Há "custos ambientais fixos" de energia e água, produção e deposição de resíduos e emissão de esgoto, etc., na manutenção de uma residência. Estes custos, em um contexto de diminuição do tamanho médio das famílias, passam a ter maiores efeitos sobre o ambiente e recursos naturais, dado que o crescimento no número de casas implica o aumento no consumo total e a perda de eficiência por economias de escala domésticas. Além disso, as despesas com necessidades domésticas básicas, como eletrodomésticos, transportes e alimentação, têm um perfil de idade em que há consumo mais baixo em idades extremas (mais jovens e mais velhas) e alto consumo nas idades médias. A expansão do número de domicílios e a redução de seu tamanho são paralelas à multiplicação de famílias sem filhos, unipessoais e outras espécies de arranjos domiciliares em que predominam pessoas em idade adulta, logo em seu momento de maior produção e consumo potenciais; como se vê, os dois efeitos concorrem para a diminuição da eficiência e o aumento da pressão sobre os recursos naturais e o ambiente (SAWYER, 2002; MARTINE, 2007).

A pressão provocada por uma sociedade sobre o ambiente depende do padrão de consumo por ela praticado e, portanto, de sua capacidade de trabalho, produção, renda e riqueza. Nesse sentido, as mudanças populacionais, chamadas transições demográficas, correm simultâneas às transformações socioeconômicas de urbanização-industrialização (NOTESTEIN, 1953; LESTHAGHE, 1995), durante as quais a adoção de um consumo urbano-industrial implica a geração de resíduos. Estes se associam, de formas várias, aos problemas urbano-ambientais, que vão do contágio por doenças infectocontagiosas (CATAPRETA; HELLER, 1999) à contaminação de solos e águas (IBAM, 2001), da pressão desnecessária sobre os recursos (CALDERONI, 2003), dada a não prática da reutilização e da re-

\footnotetext{
${ }^{4}$ Não são comuns, no Brasil, os estudos populacionais relacionando os conceitos de ciclo de vida do domicílio e consumo familiar, especialmente no contexto da relação população e meio ambiente. Trabalhos de outras áreas, no entanto, têm aplicado a noção de ciclo de vida aos estudos que lidam com o comportamento do consumidor. Veja Saraiva Jr. (2005) e Ganzo Fernandez (2006) para estudos nas áreas de administração e engenharia, respectivamente.
} 
ciclagem, aos dilemas e custos da limpeza urbana, às inundações por obstrução de vias de drenagem, entre outros problemas.

Existem, portanto, numerosos e coerentes argumentos a favor da existência de correlação entre o padrão de consumo de uma sociedade e sua produção diária de resíduos sólidos. Assumindo também que há diferenciais de consumo em função das características socioeconômicas e demográficas, temos que diferentes populações (em estrutura etária, estrutura de arranjo de domicílios, etc.) praticam diferentes padrões de consumo, gerando resíduos sólidos urbanos de forma distinta. Indicar a existência desta relação de forma empírica é a meta das seções que se seguem.

\section{Metodologia e fontes de dados}

Informações demográficas, espaciais e de resíduos sólidos

Os dados empregados provêm do Censo Demográfico 2000 e das informações da coleta de resíduos sólidos do município de Belo Horizonte, capital do Estado de Minas Gerais. Como não foi possível empregar os dados em mais de um ponto no tempo - dos Censos de 1991 e 2000, por exemplo -, optou-se por analisar diferenciais no espaço. A unidade de análise empregada é a área de ponderação (AP) do Censo Demográfico 2000. Uma representação espacial das APs de Belo Horizonte encontra-se nos Mapas 1 e 2 da próxima seção.

A estratégia metodológica neste artigo consiste, em primeiro lugar, em uma análise descritiva e espacial das características sociodemográficas e de geração de resíduos no município de Belo Horizonte. Posteriormente, é feita uma aplicação de técnicas estatísticas multivariadas, com a intenção de perceber com maior clareza a existência de associação entre as características sociodemográficas das áreas de ponderação e a geração per capita de resíduos em Belo Horizonte. As variáveis utilizadas provêm do Censo Demográfico 2000, dos relatórios anuais de geração de resíduos sólidos da Superintendência de Limpeza Urbana (SLU) e do registro de imóveis segundo condição de uso residencial, não residencial ou desocupação, organizado pela Secretaria Municipal de Fazenda da Prefeitura de Belo Horizonte (SMF-PBH). Em virtude da disponibilidade de dados populacionais do Censo Demográfico apenas para 2000, foram empregados, na aplicação dos métodos estatísticos, somente dados de geração de resíduos do ano de 2002, dada sua maior adequação vis-à-vis os dados gerados pela SLU para 2000.5 Segundo a própria natureza das fontes consideradas, as variáveis foram agrupadas em:

- Informações socioeconômicas e demográficas. Esse grupo, mais extenso e diversificado, pode ser subdividido em dois: socioeconômico e demográfico. $\mathrm{O}$ primeiro engloba as variáveis relativas à renda e ao nível de escolaridade formal da população. $O$ grupo de variáveis mais estritamente demográficas é formado por aquelas referentes a tamanho e taxa de crescimento da população, características de arranjo domiciliar e estrutura etária da população da área.

- Resíduos sólidos. A SLU, autarquia responsável pela gestão de RSUs em Belo Horizonte, foi criada na década de 1970 e, desde então, vem produzindo dados sobre produção, composição, distribuição espacial e gestão dos resíduos. A coleta de resíduos é realizada por caminhões nas nove regionais administrativas da cidade. Cada regional é dividida em certo número de distritos de coleta, que constituem a rota percorrida por um caminhão da frota da SLU. Esta rota é determinada de acordo com a trajetória que um caminhão pode percorrer sem ter de vencer grandes obstáculos do traçado urbano. Após

\footnotetext{
5 Embora haja dados disponíveis da SLU para 2000, sua compatibilização com dados do Censo 2000 foi considerada problemática, em função da ambiguidade dos dados em relação a diversos distritos de coleta.
} 
completar sua capacidade de carga, cada caminhão segue para a estação de transbordo ou o aterro onde seu conteúdo é pesado e depositado. Os dados da coleta, registrados diariamente, são agregados em relatórios anuais. Desde 2002 estas informações vêm sendo organizadas em uma malha digital em Sistemas de Informação Geográfica (SIG), permitindo o registro digital da distribuição espacial dos resíduos da cidade.

A base de dados da SLU possui uma limitação importante no que tange à definição estrita do que são os resíduos sólidos domiciliares. ${ }^{6}$ Isso porque a coleta por caminhões cobre tanto residências como estabelecimentos comerciais definidos como "de pequeno porte". Para lidar com esse obstáculo, recorreu-se às informações do registro de imóveis segundo condição de uso residencial, não residencial ou desocupação, organizado pela Secretaria Municipal de Fazenda da Prefeitura de Belo Horizonte (SMF-PBH). A variável incluída foi o percentual de domicílios por área, segundo sua condição de ocupação em 2007.7 Este artifício não anula o problema, mas permite lidar mais esclarecidamente com este fator de confusão dos dados.

- Espaço urbano. Esse grupo define o percentual, por área de ponderação, de endereços residenciais, não residenciais e "territoriais" - isto é, endereços fora de uso, residenciais ou não. Os censos demográficos brasileiros constituem uma importantíssima e regular fonte de dados demográficos, pelo menos desde 1960. A partir do Censo de 1991, os questionários passaram a incorporar um quesito sobre a destinação dos resíduos do domicílio (HAKKERT, 1996). Os microdados das variáveis da amostra podem ser associados aos indivíduos e domicílios. No entanto, o maior nível de desagregação a que estes dados da amostra atingem são as áreas de ponderação (APs), definidas como "unidade geográfica, formada por um agrupamento mutuamente exclusivo de setores censitários, para a aplicação dos procedimentos de calibração das estimativas com as informações conhecidas para a população como um todo" (IBGE, 2000, p. 12). As APs são, então, a menor unidade territorial a que se aplicam, com a significância estatística, os dados do questionário da amostra.

\section{O "problema da coexistência espacial" e a compatibilização dos dados de geração de resíduos}

Com o emprego de um Sistema de Informação Geográfica (SIG), é possível fazer a conjugação das malhas dos distritos de coleta e das APs e definir o pertencimento perfeito ou aproximado de cada conjunto de distritos a uma ou mais APs. Torres (2005) denomina esta situação de "o problema da coexistência espacial", isto é, o analista precisa observar dois fenômenos diferentes "acontecendo, ao mesmo tempo, no mesmo lugar" (TORRES, 2005, p. 318). Em nosso caso, trata-se de

\footnotetext{
${ }^{6}$ A definição do que seja de fato lixo domiciliar constitui na legislação urbana brasileira uma zona cinzenta. A legislação de Belo Horizonte que reza sobre o assunto diz: "considera-se lixo domiciliar para fins de coleta regular, os produzidos pela ocupação de imóveis públicos ou particulares, residenciais ou não, acondicionáveis na forma estabelecida por esta Lei". A mesma lei define "por acondicionamento, o ato de embalar em sacos plásticos ou em outras embalagens descartáveis permitidas, de acomodar em recipientes ou em recipientes padronizados, os resíduos sólidos para fins de coleta e transporte". Em verdade, a indefinição torna flexível a gestão do problema, que seria bastante incômodo em caso de diferenciação estrita dos geradores segundo classes bem definidas. A norma em questão é a Lei n. 2.968, de 3 de agosto 1978. Constam várias alterações posteriores desta lei, mas nenhuma que definisse mais claramente a matéria. 7 O emprego dos dados deste ano, 2007, se deu em função de sua disponibilidade. Não havia a informação disponível para anos anteriores, logo empregamos a disponível. A relativa inércia da composição do espaço urbano, refratário a grandes recomposições em períodos curtos, minimiza, embora não anule, o problema do descolamento temporal desses dados com os do Censo Demográfico e da SLU sobre os resíduos sólidos urbanos.
} 
lidar com a coexistência espacial das variáveis sociodemográficas e de geração de resíduos, a coexistência espacial de áreas de ponderação do Censo Demográfico 2000 e distritos de coleta da SLU.

A compatibilização das áreas deve considerar dois aspectos importantes. Primeiro, é necessário escolher a camada que prevalece quanto à abrangência territorial. No caso do presente estudo, o conjunto de polígonos que será reestruturado é dos distritos de coleta, que se adaptam à nova configuração ditada pela estrutura territorial das APs. Em segundo lugar, há problema da distribuição espacial das variáveis internamente a cada área. Este artigo analisa diferenciais de geração de resíduos sólidos entre as APs, logo, abdicamos da análise dos diferenciais internos a cada área, em termos tanto da geração de resíduos quanto da heterogeneidade demográfica de cada AP.

No entanto, como os distritos foram agregados para se ajustar aos limites das APs, houve necessidade de fazermos duas suposições. Destacamos que o registro da produção de resíduos é feito com referência a cada distrito de coleta, e nada se diz quanto à possível heterogeneidade interna a cada um deles. Logo, na ausência de melhor informação, precisamos assumir que:

- a quantidade produzida é homogeneamente distribuída dentro da área de cada distrito;

- a quantidade produzida é diretamente proporcional à área do distrito, isto é, em cada percentual $x$ de área se produz igual percentual da produção total de resíduos do distrito.

Tais pressupostos são necessários para solucionar o problema da compatibilização. Cada área de ponderação encerrará a geração de resíduos que corresponde à soma da geração dos distritos com as quais coexistem espacialmente. Além disso, a produção daqueles distritos que forem divididos entre distintas APs será distribuída entre estas na proporção do percentual de área que participar de cada AP. Torres (2005) propõe procedimento análogo para estimar a população de uma área de interesse sobre a qual não há informação desagregada, mas que coexiste espacialmente com outra para a qual o censo demográfico fornece este dado.

\section{As técnicas estatísticas multivariadas}

Tendo em vista o objetivo de identificar diferenciais intraurbanos na produção de resíduos sólidos em Belo Horizonte a partir de diferenciais sociodemográficos, avaliamos a possível existência de perfis distintos de regiões no interior do tecido urbano. A hipótese é de que haveria conjuntos díspares de áreas de ponderação em termos da geração per capita de resíduos sólidos domiciliares coletados pela SLU, o que levaria à formação de conjuntos de APs que se assemelharão entre si, e conjuntos que se diferenciarão de outros conjuntos.

Partindo da noção de que a maioria das variáveis se comporta de modo fortemente associado, a opção foi aplicar aos dados as chamadas técnicas de análise multivariada, particularmente a Análise de Componentes Principais (ACP) e a Análise de Conglomerados ou Clusters. Estas técnicas têm sido aplicadas com frequência em estudos de cunho regional e urbano, apresentando resultados interessantes e coerentes (QUEIROZ, 2003).

As técnicas de análise multivariada têm como característica comum a busca de "parâmetros-resumo" que sintetizem a relação entre determinado conjunto de variáveis. Dentro desta perspectiva, a técnica dos componentes principais imprime tratamento estatístico a um número relativamente alto de variáveis que possuam elevada correlação, condensando o conjunto inicial de variáveis em um número reduzido. Aquele conjunto inicial fica representado em um pequeno número de índices - os componentes principais, os quais sintetizam o comportamento assumido pelo conjunto e podem também ser utilizados para "representar um conjunto de variáveis em outras técnicas multivariadas, como a análise de clusters, além de permitir uma hierarquia de indivíduos ou unidades de observação" (QUEIROZ, 2003).

Em termos matemáticos, o método $\mathrm{ACP}$ - e outros métodos de estatística multivariada - baseia-se no chamado teorema da decomposição espectral, o qual decompõe 
a matriz de covariância original em matrizes de autovalores e autovetores (MINGOTI, 2005). Os componentes são novas variáveis definidas como combinações lineares das originais. Os autovetores representam o peso de cada variável no cálculo do componente.

Como esses componentes têm a virtude de serem parâmetros-resumo do comportamento do conjunto inicial das variáveis, é possível escolher um pequeno número de componentes - em geral os iniciais que expressam maior percentual da variância do conjunto - e analisar apenas estes, entendendo o maior ou menor peso de cada variável sobre ele. Pode-se, então, analisar cada um dos componentes escolhidos como uma dimensão específica do problema em questão.

Identificadas as dimensões principais que distinguem os indivíduos, é importante tornar claro quais deles têm maior grau de semelhança. Um recurso eficiente para isso é a aplicação conjunta da técnica de componentes principais e de uma técnica de classificação, por exemplo, a técnica de clusters. As técnicas de classificação são indicadas quando os elementos da tabela inicial de dados são classificáveis, implicando, caso os indivíduos estejam dispostos no espaço, a existência de zonas de alta densidade de indivíduos; e entre elas haverá uma baixa densidade de indivíduos (MINGOTI, 2005). Essa semelhança pode ser avaliada por meio de índices de (dis)similaridade denominados de "distâncias". A mais usual das formas de cálculo para essa distância é a chamada "distância euclidiana".

As análises de cluster admitem abordagens hierárquicas e abordagens de partição. As primeiras consideram que de início cada individuo se encontra isolado, como que formando um "cluster individual". O processo segue aproximando estes indivíduos de acordo com suas similaridades até que se atinja uma estabilidade relativa, que variará em função dos objetivos do trabalho. As técnicas de partição operam em sentido contrário, "desaglomerando" um cluster único inicial. A opção foi feita por empregar a abordagem hierárquica. Os agrupamentos serão, então, representados graficamente por dendogramas que ilustram, graficamen- te, tanto as possíveis aglomerações como a sua consistência relativa que varia em função da "proximidade" entre os indivíduos em termos da distância euclidiana.

\section{Aspectos sociodemográficos, urbano- espaciais e de geração de resíduos sólidos domiciliares em Belo Horizonte}

\section{Análise descritiva}

Nesta seção são apresentadas informações sobre diferenciais socioeconômicos e demográficos entre as áreas de ponderação (APs) de Belo Horizonte, assim como no tocante à produção de resíduos sólidos urbanos.

As 58 áreas de ponderação de Belo Horizonte tinham, em 2000, uma média de população de aproximadamente 38.595 pessoas, sendo que a menos populosa, AP Planalto, contava com 15.798 habitantes e a mais populosa, AP Cristiano Machado, com 73.343 (Tabela 1).

Não se identifica um padrão regular de distribuição da população de Belo Horizonte pelas áreas de ponderação. Já a densidade demográfica por área apresentava, em 2000, tendência a ser menor nas regiões periféricas da capital e mais alta nas APs próximas da região centro-sul. Este também é o padrão assumido pelo gradiente de renda e escolaridade nos domicílios da capital mineira, fatos entre si coerentes. Sabe-se que Belo Horizonte surge como cidade planejada, embora apenas uma pequena parte de seu território atual corresponda à planta original, a área central da cidade, que - seguindo a inércia característica dos processos socioespaciais - permanece como centralidade mais importante e organiza em seu entorno as fatias mais valorizadas pelo mercado imobiliário (MONTE-MÓR, 1994). Este fato implicou a verticalização e o adensamento demográfico tanto quanto econômico: domicílios de alta renda lado a lado com áreas com forte oferta de serviços urbanos de toda espécie, como é constitutivo de centralidades de grande porte.

A presença de vilas ou favelas - os aglomerados subnormais - concorre para o adensamento das APs, de forma que 
TABELA 1

População residente, segundo regionais e áreas de ponderação Município de Belo Horizonte - 2000

\begin{tabular}{|c|c|c|c|c|c|}
\hline Regionais e APs & População & Regionais e APs & População & Regionais e APs & População \\
\hline Barreiro & 259.866 & Nordeste & 272.807 & Oeste & 266.507 \\
\hline Bairro das Indústrias & 10.891 & Capitão Eduardo & 7.472 & Cabana & 69.095 \\
\hline Lindéia & 51.302 & Ribeiro de Abreu & 23.486 & Jardim América & 71.032 \\
\hline Barreiro de Baixo & 40.870 & Belmonte & 41.833 & Barroca & 48.259 \\
\hline Barreiro de Cima & 54.543 & Gorduras & 14.546 & Morro das Pedras & 21.290 \\
\hline Jatobá & 61.767 & São Paulo/Goiânia & 60.830 & Betânia & 40.901 \\
\hline Cardoso & 32.995 & Cristiano Machado & 73.898 & Estoril/Buritis & 15.930 \\
\hline Olhos d'Água & 5.229 & Cachoeirinha & 32.931 & & \\
\hline Barreiro-Sul & 2.269 & Concórdia & 17.812 & & \\
\hline Centro-Sul & 259.971 & Noroeste & 338.083 & Pampulha & 139.796 \\
\hline Barro Preto & 6.340 & Glória & 69.549 & Garças/Braúnas & 4.833 \\
\hline Centro & 14.553 & Abílio Machado & 49.038 & Santa Amélia & 31.098 \\
\hline Francisco Sales & 8.452 & Jardim Montanhês & 17.108 & Pampulha & 11.626 \\
\hline Savassi & 46.273 & Caiçara & 37.041 & Jaraguá/UFMG & 30.293 \\
\hline Prudente de Morais & 17.328 & Antônio Carlos & 59.000 & Sarandi & 25.951 \\
\hline Santo Antônio & 28.549 & Padre Eustáquio & 48.385 & Castelo & 8.710 \\
\hline Anchieta/Sion & 42.876 & Camargos & 2.452 & Ouro Preto & 15.759 \\
\hline Serra & 22.956 & PUC & 31.336 & São Francisco & 7.689 \\
\hline Mangabeiras & 6.956 & Santa Maria & 14.970 & Confisco & 3.835 \\
\hline São Bento/Sta. Lúcia & 13.201 & Prado Lopes & 9.205 & & \\
\hline Belvedere & 4.599 & & & & \\
\hline Barragem & 14.743 & & & & \\
\hline Cafezal & 33.145 & & & & \\
\hline Leste & 254.190 & Norte & 191.452 & Venda & 242.873 \\
\hline Instituto Agronômico & 43.587 & Jaqueline & 27.616 & Mantiqueira/Sesc & 43.967 \\
\hline Boa Vista & 46.862 & Isidoro Norte & 7.285 & Serra Verde & 16.929 \\
\hline Floresta/Santa Tereza & 33.861 & Furquim Werneck & 4.462 & Piratininga & 46.865 \\
\hline Pompéia & 26.644 & Planalto & 15.771 & Jardim Europa & 26.960 \\
\hline Taquaril & 39.392 & São Bernardo & 29.781 & Venda Nova & 16.665 \\
\hline Santa Efigênia & 41.092 & Tupi/Floramar & 53.007 & Céu Azul & 26.826 \\
\hline Baleia & 8.175 & Primeiro de Maio & 35.978 & Copacabana & 50.714 \\
\hline Mariano de Abreu & 5.195 & Jardim Felicidade & 17.553 & São João Batista & 13.947 \\
\hline Santa Inês & 9.383 & & & & \\
\hline
\end{tabular}

Belo Horizonte

Fonte: IBGE. Censo Demográfico 2000.

algumas das APs mais densas são aquelas onde estes aglomerados se localizam: a forma de ocupação dessas áreas, seguindo parâmetros peculiares de formação, contribui para o adensamento por unidade de área. Em Belo Horizonte, algumas das vilas mais representativas em termos de tamanho populacional estão justamente nas regionais leste e centro-sul, embora estas não sejam as áreas da cidade onde predominam domicílios de baixa renda (PINHEIRO, 2007).

E como as periferias do município emergem enquanto processos histórico-espaciais? Aí também o que se nota é que a ação do Estado e, secundariamente, alguns grandes investimentos privados foram fundamentais para a organização dos espaços periféricos da capital (SILVA; AMARAL; SIMÕES, 2008). Interagindo com núcleos 
de povoamento já instalados nos primeiros tempos da capital, como Venda Nova e Barreiro, a extensão da infraestrutura urbana - especialmente na instalação de grandes vias urbanas e também rodovias - orientou os vetores principais de crescimento da cidade e também do adensamento com os municípios vizinhos, como Contagem, Betim, Santa Luzia, Vespasiano e Sabará (BRITO; SOUZA, 1998).

Como síntese dessas dinâmicas, configura-se no espaço urbano da capital um gradiente bem marcado, que decresce de intensidade a partir do centro em direção às periferias, de distribuição da população em níveis de renda e escolaridade. Além disso, fato fundamental para a discussão e que será abordado na próxima seção, verifica-se gradiente semelhante de características demográficas: idade média da população e do chefe do domicilio; estrutura etária; tamanho de domicílios; número de filhos residentes; percentual de domicílios unipessoais; percentual de população com 60 anos e mais; entre outros indicadores sociodemográficos. ${ }^{8}$

A hipótese de trabalho, como já dito, é que características socioeconômicas e demográficas da população refletem (e são refletidas em) seu padrão de consumo - seja pela via de sua capacidade potencial de geração de renda (BARROS et al., 2004), seja como implicação de seu padrão de consumo (PRINCEN, 1999) -, afetando, de alguma forma, seu regime de produção de RSUs.
Ao longo do período 1975-2006, ${ }^{9}$ a produção de RSUs no município de Belo Horizonte teve uma ampliação notável do volume, assim como da quantidade per capita gerada pela sua população. Em 1975, Belo Horizonte possuía 1.557.464 habitantes e registrava uma produção total ${ }^{10}$ de 141.939,33 toneladas de resíduos sólidos, o que equivalia a $0,25 \mathrm{~kg}$ per capita por dia. A produção registrada de resíduos sólidos na capital mineira cresceu levemente durante os anos 1970 até meados da década seguinte, aumentando em ritmo acelerado a partir daí11 (Gráfico 1).

A produção de resíduos per capita diária passou de 0,38 kg, em 1980, para 0,56 kg, em 1990, e ultrapassou 1,0 kg em 1997 (1,09 $\mathrm{kg}) .^{12} \mathrm{Em} 2000$, registrava-se uma produção de $1,16 \mathrm{~kg}$ e, em 2005, 1,26 kg/habitante/dia. A variação percentual anual da produção tem um comportamento irregular (Gráfico 2), mas observando sua tendência, nota-se que, mesmo diante do fortíssimo aumento absoluto da produção nos anos 1990, houve queda do ritmo de crescimento, que inclusive chegou a ser negativo em anos recentes. ${ }^{13}$

Belo Horizonte chegou ao início do século XXI com uma população acima de 2,3 milhões de habitantes, sendo que os problemas da capital são, há muito tempo, computáveis no âmbito metropolitano e não mais no municipal. ${ }^{14}$ Analisados em sua trajetória recente, os ritmos de crescimento

\footnotetext{
8 Para uma extensa exposição dos diferenciais sociodemográficos entre as APs do município de Belo Horizonte, ver Silva (2008).

${ }^{9}$ Esse período coincide com a existência da SLU e o registro feito por esse órgão da produção de RSUs em Belo Horizonte.

${ }^{10}$ Esse montante não é diferenciado nos dados obtidos da SLU. O mais provável é que aí se incluam todas as modalidades de resíduos sólidos urbanos: domiciliar, comercial, público e industrial.

11 Há a possibilidade de que parte deste incremento durante a década de 1980 e anos seguintes seja um reflexo tanto do aumento da cobertura do serviço de coleta, quanto da melhora do serviço de registro das quantidades produzidas/ coletadas. Não temos, no entanto, dados para elucidar a dúvida. Ficam, porém, o alerta e a possibilidade de estimar as cifras reais em outros trabalhos.

12 A população anual utilizada aqui é estimada. Dados disponíveis em <www.datasus.gov.br>

13 Devemos ter cuidado com a análise de curto prazo desta curva, já que alterações nas regras de registro têm impacto nos dados registrados, como no caso da inclusão a partir de 1996 dos resíduos sólidos de construção civil no cômputo do total aterrado (BELO HORIZONTE, 2006). O caso específico dos resíduos de construção civil merece uma reflexão a parte, não apenas pelo tamanho da geração anual, mas também pelo papel da construção e reconstrução do espaço nas economias capitalistas (HARVEY, 2005).

14 Na Região Metropolitana de Belo Horizonte (RMBH), residiam, em 2000, 4,3 milhões de pessoas. Segundo a mais recente estimativa, Belo Horizonte possui 2.412.937 habitantes, contra 4.939.053 da RMBH. O problema da gestão de RSUs assumiu recentemente cores metropolitanas mais dramáticas na capital, desde que o seu único aterro sanitário atingiu sua capacidade máxima, obrigando a administração municipal a negociar a deposição no município vizinho de Sabará.
} 
GRÁFICO 1

Evolução da produção de resíduos sólidos - total produzido e descontada produção de resíduos de construção civil (RSCC) (1) - e parcela reciclada

Município de Belo Horizonte - 1975-2006

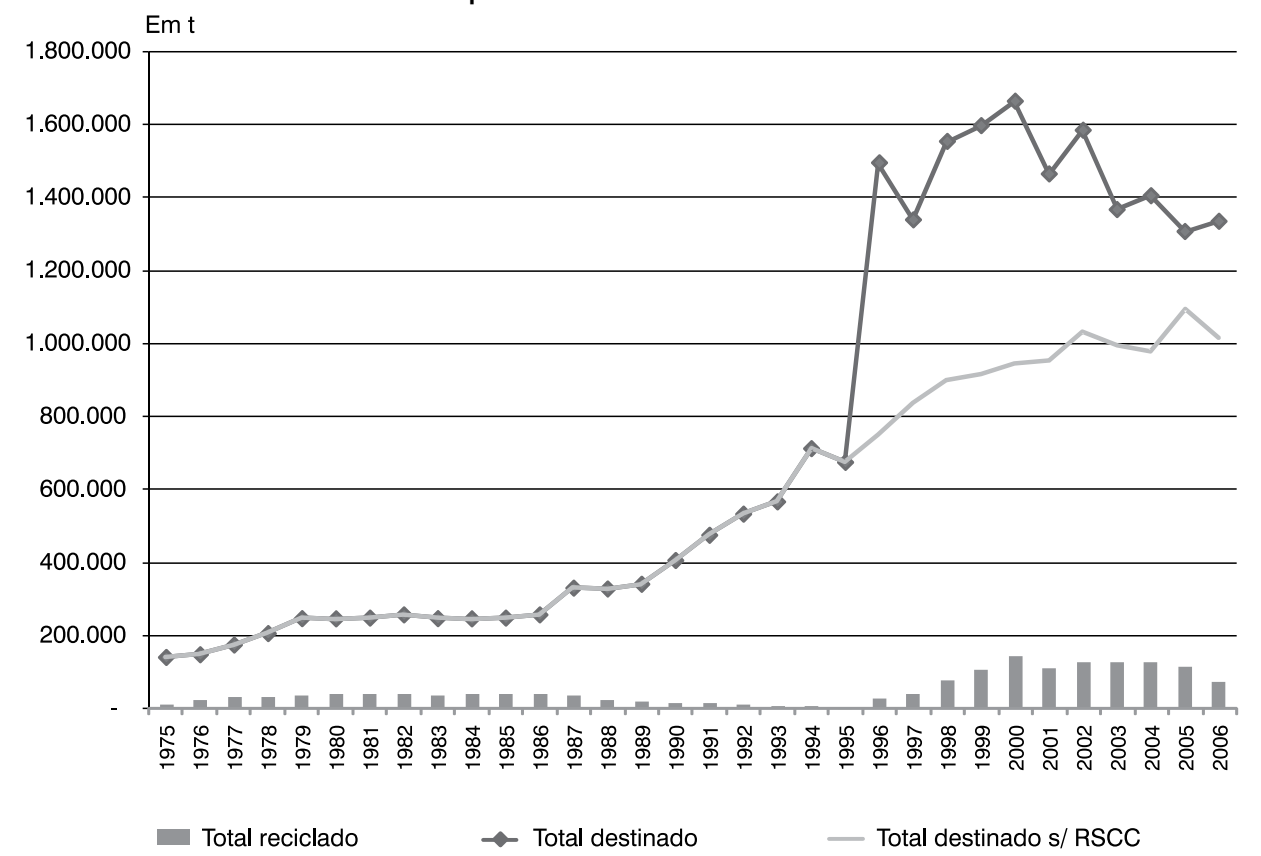

Fonte: Secretaria Municipal de Limpeza Urbana - SLU 2006.

(1) A partir de 1996, a SLU passou a computar os resíduos sólidos produzidos pela construção civil como parte do total aterrado; por isso a forte divergência entre as duas curvas de "Total destinado" e "Total destinado s/RSCC" a partir desse ano.

\section{GRÁFICO 2}

Geração per capita anual e diária de resíduos sólidos e variação percentual anual da quantidade produzida Município de Belo Horizonte - 1975-2006

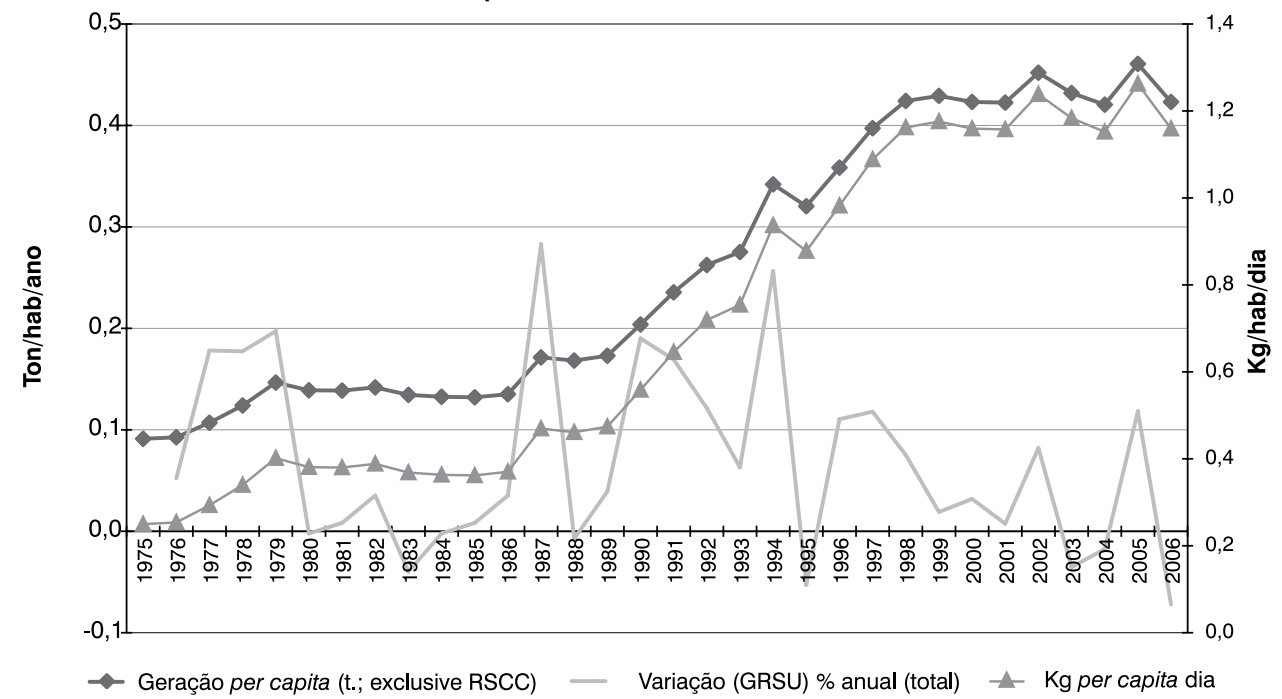

Fonte: Datasus (população); Secretaria Municipal de Limpeza Urbana - SLU 2006.

Nota: RSCC: resíduos sólidos da construção civil. 
da população e do total de resíduos sólidos produzidos dão sinais de arrefecimento (Gráfico 3). Comparando as trajetórias, no entanto, nota-se que o ritmo de crescimento da população foi menor do que o da produção de resíduos, especialmente durante os anos 1990, indicando que fatores socioeconômicos e demográficos, que não apenas tamanho e taxa de crescimento, representaram papel importante na geração deste problema urbano (Gráfico 3). ${ }^{15}$

A distribuição da produção de resíduos sólidos domiciliares ${ }^{16}$ entre as nove regionais administrativas do município mostra forte proeminência da regional Centro-Sul, seguida pela Noroeste. A participação de cada regional na geração dos resíduos sólidos domiciliares segue mais ou menos o padrão de distribuição da população e dos domicílios pelas regionais. A Centro-Sul, no entanto, se destaca por ter maior participação no número de domicílios e ainda mais fortemente na geração de resíduos (em torno de $20 \%$ ) do que na população total $(11,7 \%$ em 2000). Este descompasso se repete, ainda que de forma menos pronunciada, na regional Pampulha.

As regionais Oeste e Noroeste têm peso praticamente idêntico nas três variáveis, enquanto nas de Barreiro, Norte, Venda Nova e Leste a participação percentual na geração de resíduos sólidos domiciliares é menor do

GRÁFICO 3

Evolução comparada da população total e da produção de resíduos sólidos urbanos (1) Município de Belo Horizonte - 1980-2006

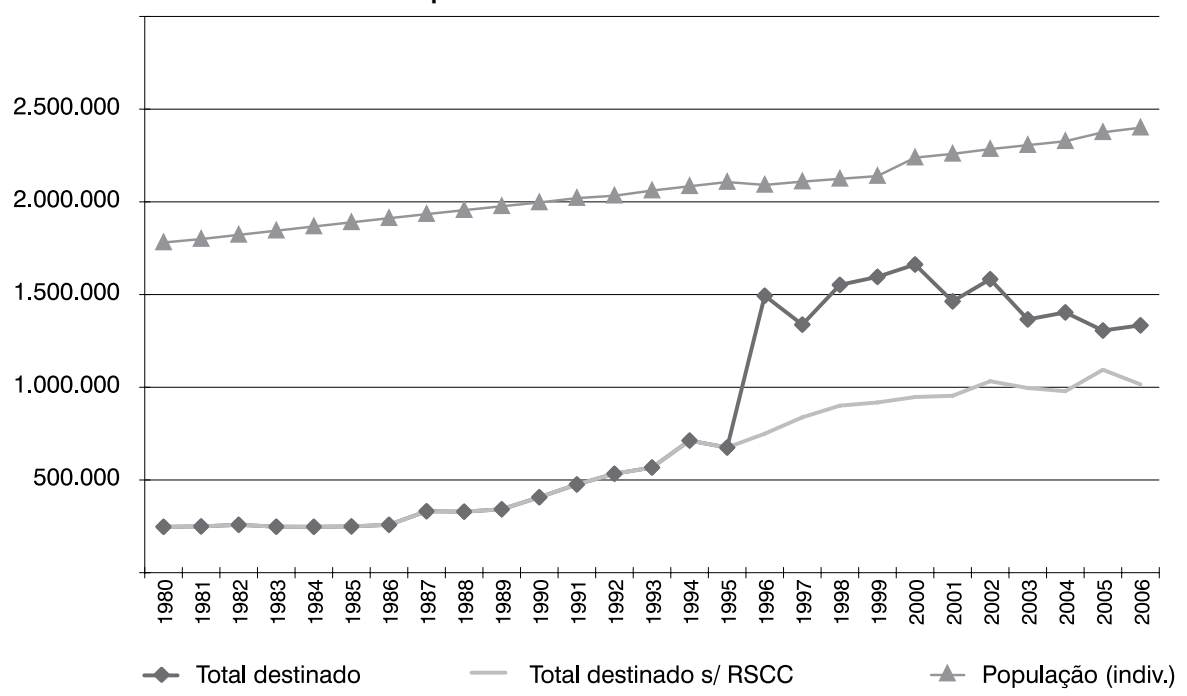

Fonte: IBGE. Censo Demográfico 2000; Ministério da Saúde. Datasus; Secretaria Municipal de Limpeza Urbana - SLU 2006.

(1) A partir de 1996, a SLU passou a computar os resíduos sólidos produzidos pela construção civil como parte do total aterrado; por isso a forte divergência entre as duas curvas de "Total destinado" e "Total destinado s/RSCC" a partir desse ano.

\footnotetext{
15 Há uma grande discussão a ser feita nesse ponto, não desconhecida ou desconsiderada, mas que escapa ao escopo do trabalho. Esta é sobre a transição urbana, de consequências extensas, pela qual passou a sociedade no Brasil ao longo deste quarto de século, 1975-2000, especialmente no que respeita à difusão de condições de consumo coletivo urbano e condições gerais de produção (COSTA; MONTE-MÓR, 2002). O fato de que tenha havido um salto da produção per capita de RSU de 0,25 para 1,26 kg/dia - volume cinco vezes maior - reflete uma mudança qualitativa brutal no nível, estrutura e distribuição espacial das condições de consumo no capitalismo brasileiro, cujo estudo de casos locais, como Belo Horizonte, ajudaria a tornar mais clara. Por hora, voltemos aos aspectos sociodemográficos.

16 Como mencionado em nota anterior, o termo resíduo domiciliar não se refere apenas aos resíduos gerados em residenciais, mas também àqueles advindos de estabelecimentos comerciais de pequeno porte, que gerem resíduos até o limite diário permitido.
} 
que no total de população residente (Gráfico 4). Este último grupo é formado justamente por regionais com perfil socioeconômico menos privilegiado - em termos de renda e educação - e perfil demográfico domiciliar mais "tradicional", isto é, famílias com maior número de filhos, idade média da população mais baixa, chefes de domicílio mais jovens e menor incidência de domicílios unipessoais. A exceção a esta descrição é a regional Leste, onde, no entanto, são mais abundantes os setores subnormais.

Considerando a distribuição da produção dos resíduos sólidos domiciliares segundo as áreas de ponderação, a diferenciação entre a participação na população residente em 2000 e a quantidade produzida é mais pronunciada. Como é usual considerar a geração per capita enquanto índice de intensidade de produção de resíduos em uma população, analisamos o status de cada área como geradora, construindo uma medida simples: a razão entre a participação percentual da AP no total de população residente e na geração total de resíduos domiciliares coletados. Um índice igual à unidade indica que a população desta AP gera resíduos em consonância com seu peso na distribuição espacial da população na cidade. Definimos como "sobreparticipação" da área na geração de resíduos o índice acima de um e vice-versa.

Conforme o Mapa 1, para 31 áreas de ponderação $(53,5 \%)$, a participação na geração de resíduos é menos que proporcional ao seu peso populacional. Entre essas, 12 (20\%) têm participação proporcional até $30 \%$ menor. A participação menos que proporcional na geração aparece especialmente em Barreiro, Venda Nova e Norte. A regional Oeste tem a combinação mais diversa: a AP Estoril/Buritis no topo da escala, gerando resíduos em proporção elevada (acima de duas vezes o seu peso populacional), ao lado das APs do grupo menos representativo (Morro das Pedras e Cabana) e intermediário (Barroca, Betânia e J. América). Além de Estoril/Buritis, aparecem no grupo de maior sobreparticipação Barro Preto e Savassi, nas regionais Centro-Sul e Pampulha. Há uma

GRÁFICO 4

Distribuição da população residente, dos domicílios e da produção de resíduos sólidos domiciliares, segundo regionais administrativas

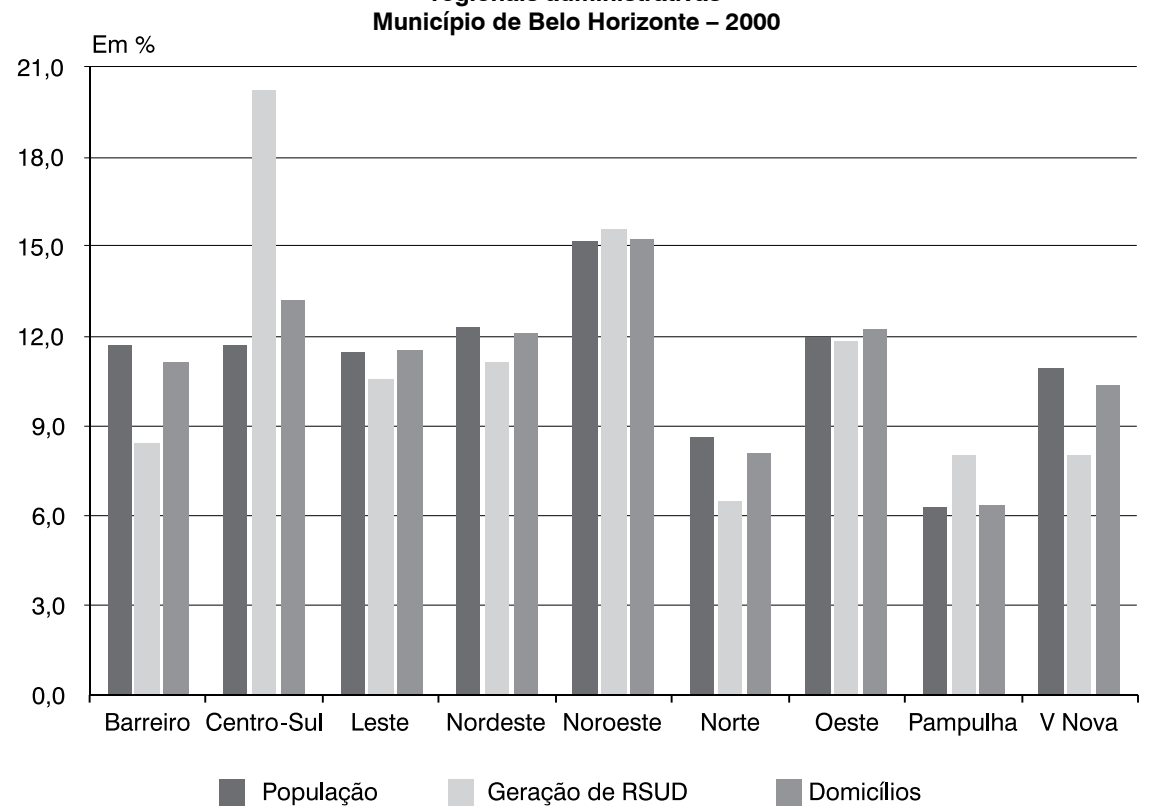

Fonte: IBGE. Censo Demográfico 2000; Secretaria Municipal de Limpeza Urbana - SLU 2000. Nota: RSUD: resíduos sólidos urbanos domiciliares. 
MAPA 1

Razão entre participação percentual na população residente e na geração de resíduos sólidos domiciliares, segundo áreas de ponderação

Município de Belo Horizonte - 2000

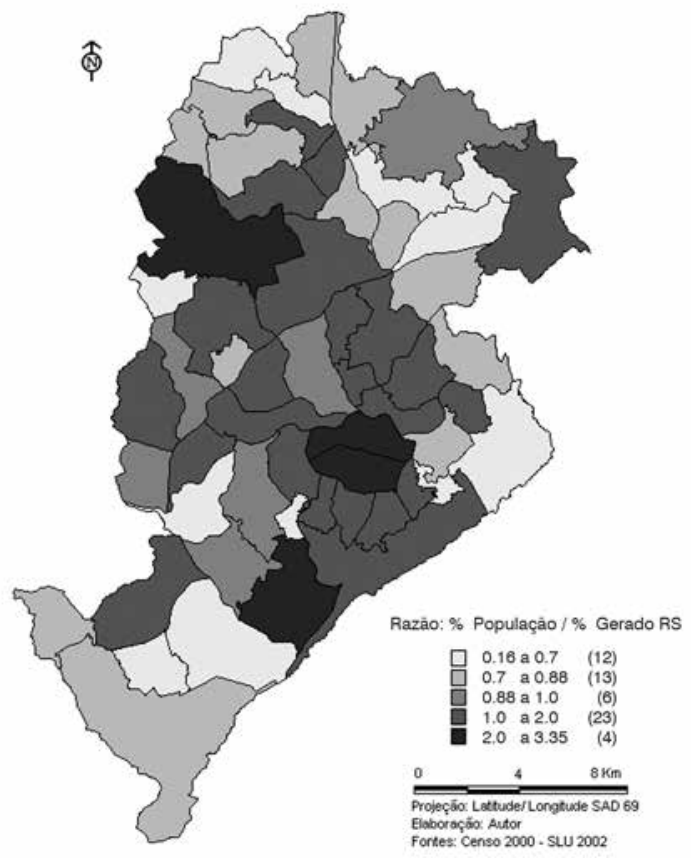

Fonte: IBGE. Censo Demográfico 2000; Secretaria Municipal de Limpeza Urbana - SLU 2000.

faixa central do território do município, de sudeste e noroeste do mapa, onde predomina alta geração. Fora desta aparecem a AP Barreiro de Baixo, região tradicionalmente densa e com elevada oferta de serviços (LEMOS et al., 2004), e Capitão Eduardo. ${ }^{17}$

\section{Análise de componentes principais}

A Tabela 2 apresenta estatísticas descritivas das variáveis utilizadas na Análise Componentes Principais (ACP). Este método permite calcular tantos componentes quantas forem as variáveis trabalhadas.
No entanto, um dos aspectos atraentes do método é sua capacidade de condensar a variabilidade do sistema em poucos componentes, ou mesmo em um ou dois. A proporção de variância explicada declina à medida que passamos do primeiro componente aos subsequentes, ainda que somente a soma de todos os componentes corresponda a toda variância do sistema.

Uma regra de bolso usual é de que o ponto de corte, no qual se deixa de incluir novos componentes na análise, é a partir do ponto em que o diferencial de explicação pela inclusão passa a ser muito discreto

\footnotetext{
17 Esta ultima é um caso intrigante e de difícil explicação. Capitão Eduardo é uma das regiões onde há mais baixa densidade populacional média, possuindo áreas verdes extensas. Essa não é, entretanto, uma peculiaridade muito elucidativa, pois o Barreiro é a uma região com grande área verde e não se destaca em sobreparticipação, a não ser na AP mais intensamente comercial, Barreiro de Baixo. Ao mesmo tempo, a Pampulha, também com grande percentual de área verde, está no topo da distribuição de sobreparticipação. No caso da Pampulha, merece menção o fato de que é pequena a presença de endereços não residenciais. As UPs Gorduras e Capitão Eduardo - que formam a AP Capitão Eduardo - são a quarta e oitava, respectivamente, em presença de área verde (www.pbh.gov.br). Quanto à densidade populacional, as UPs que formam a AP Capitão Eduardo têm densidades de 1.311,2 (Capitão Eduardo), 2.030,6 (Gorduras) e 7.423,8 (Ribeiro de Abreu) habitantes por $\mathrm{km}^{2}$, contra $8.828,8 \mathrm{~km}^{2}$ do município.
} 
TABELA 2

Estatísticas básicas para variáveis socioeconômicas, demográficas e de resíduos sólidos Município de Belo Horizonte - 2000

\begin{tabular}{|c|c|c|c|c|c|c|}
\hline Grupo & Código & Variável & Média & $\begin{array}{l}\text { Desvio- } \\
\text { Padrão }\end{array}$ & Min. & Max. \\
\hline $\begin{array}{l}\text { Geração de } \\
\text { resíduos }\end{array}$ & rspc02 & Resíduo per capita & 0,23 & 0,12 & 0,04 & 0,73 \\
\hline \multirow{4}{*}{$\begin{array}{c}\text { Tamanho } \\
\text { e taxa de } \\
\text { crescimento }\end{array}$} & pop & População residente & $38.595,3$ & $16.449,8$ & $15.800,0$ & $73.340,0$ \\
\hline & ndomic & Número de domicílios & $1.095,2$ & 464,8 & 429,0 & $2.180,0$ \\
\hline & denspop & Densidade populacional (hab./km²) & $1.563,8$ & 821,7 & 133,2 & $4.369,5$ \\
\hline & txcres & $\begin{array}{l}\text { Taxa anual de crescimento da população 1991-2000 } \\
\text { (\%) }\end{array}$ & 1,7 & 3,0 & $-2,1$ & 20,3 \\
\hline \multirow{3}{*}{$\begin{array}{l}\text { Idade do } \\
\text { chefe }(\%)\end{array}$} & chjovem & Chefes com menos de 30 anos & 13,3 & 4,1 & 4,1 & 22,9 \\
\hline & chadulto & Chefes entre 30 e 59 anos & 67,0 & 4,2 & 4,2 & 79,2 \\
\hline & chidoso & Chefes maiores de 60 anos & 19,7 & 6,4 & 6,2 & 34,8 \\
\hline \multirow{7}{*}{$\begin{array}{l}\text { Tipo de } \\
\text { arranjo } \\
\text { domiciliar } \\
\text { (\%) }\end{array}$} & unipes & Domicílios unipessoais & 3,4 & 2,1 & 1,7 & 14,2 \\
\hline & sfilho & Casais sem filhos & 14,6 & 6,4 & 6,4 & 46,2 \\
\hline & umfilho & Casais com 1 filho & 20,7 & 2,2 & 2,2 & 26,8 \\
\hline & dfilhos & Casais com 2 filhos & 29,9 & 2,9 & 2,9 & 36,1 \\
\hline & tfilhos & Casais com 3 filhos & 20,5 & 2,9 & 2,9 & 25,5 \\
\hline & qfilemais & Casais com 4 filhos e mais & 14,3 & 6,0 & 3,0 & 29,8 \\
\hline & desvtd & $\begin{array}{l}\text { Desvio-padrão do número de moradores do } \\
\text { domicílio }\end{array}$ & 1,9 & 0,2 & 0,2 & 2,5 \\
\hline \multirow{4}{*}{$\begin{array}{l}\text { Estrutura } \\
\text { etária }\end{array}$} & idmedar & Média de idade da população & 30,1 & 3,6 & 24,3 & 40,0 \\
\hline & pop0_14 & População de 0 a 44 anos (\%) & 24,6 & 5,4 & 5,4 & 35,4 \\
\hline & pop15_59 & População de 15 a 59 anos (\%) & 66,4 & 2,6 & 2,6 & 72,6 \\
\hline & pop60m & População de 60 anos e mais (\%) & 8,9 & 3,8 & 3,8 & 21,6 \\
\hline \multirow{6}{*}{$\begin{array}{c}\text { Renda e } \\
\text { escolaridade }\end{array}$} & rdpc & $\begin{array}{l}\text { Média de renda domiciliar per capita (RDPC) } \\
\text { (em reais) }\end{array}$ & 585,4 & 507,3 & 134,5 & $2.239,0$ \\
\hline & 1 qrdpc & População (\%) do 1 quartil de RDPC & 24,39 & 14,72 & 0,75 & 57,59 \\
\hline & 4qrdpc & População (\%) do 4 quartil de RDPC & 26,72 & 24,74 & 0,74 & 86,51 \\
\hline & anest & Média de anos de estudo da população & 6,82 & 1,92 & 1,92 & 11,10 \\
\hline & 4qanest & População (\%) do 1 quartil de anos de estudo & 27,78 & 9,06 & 9,06 & 50,84 \\
\hline & rdpc_m & População (\%) do 4 quartil de anos de estudo & 13,86 & 14,20 & 0,87 & 49,83 \\
\hline \multirow{3}{*}{$\begin{array}{c}\text { Composição } \\
\text { residencial/ } \\
\text { comercial } \\
(\%)\end{array}$} & resid & Imóveis residenciais & 72,87 & 11,68 & 11,68 & 87,80 \\
\hline & nresid & Imóveis não residenciais & 14,03 & 9,17 & 3,21 & 65,54 \\
\hline & territ & Imóveis sem ocupação atual & 13,10 & 11,55 & 0,20 & 51,65 \\
\hline
\end{tabular}

Fonte: IBGE. Censo Demográfico 2000; Secretaria Municipal de Limpeza Urbana - SLU 2003; Secretaria Municipal de Finanças - SMF 2007.

(MINGOTI, 2005). A presente análise se limitará aos dois primeiros componentes, os quais respondem, juntos, por $65 \%$ da variância total.

No primeiro componente, as variáveis com maior peso positivo são idade média da população, domicílios chefiados por indivíduos de 60 anos e mais, renda domiciliar e escolaridade, especialmente os quartis superiores. Com peso pouco menor figuram, também, o percentual de domicílios unipessoais e o volume per capita de resíduo gerado. No polo oposto do mesmo componente estão os quartis inferiores de 
renda domiciliar e escolaridade e domicílios com três filhos e mais. Vale destacar que as variáveis população residente, número de domicílios e densidade têm pequeno peso neste componente. Entre as variáveis referentes à composição residencial ou não residencial, esta última dimensão figura positivamente, mas não entre as mais destacadas. Em suma, o primeiro componente é um índice que distingue regiões de alta renda e escolaridade, onde prevalecem uma população de alta idade média e domicílios pequenos, especialmente casais sem filho e domicílios unipessoais.

O segundo componente tem como variáveis de maior peso positivo o percentual de domicílios chefiados por adultos e o percentual de população do grupo etário 30 a 59 anos. Figuram aí, também, as variáveis taxa de crescimento 1991-2000, percentual de casais com até dois filhos e percentual de imóveis residenciais. As variáveis de peso negativo são o desvio-padrão do tamanho do domicílio, população de 60 anos e mais e o percentual de domicílios unipessoais. As variáveis socioeconômicas (escolaridade e renda), a presença de grupos etários jovens, o alto número de filhos e especialmente a variável de geração per capita de resíduos não são importantes na composição do índice.

Este segundo componente distingue regiões residenciais, onde prevalecem domicílios chefiados por adultos e domicílios pequenos. Algumas áreas associadas a este perfil no município - especialmente Estoril/ Buritis - são de ocupação relativamente recente, daí a força da variável taxa de crescimento, em função da rápida ocupação na década de 1990.

Por oposição, o componente distingue estas áreas daquelas onde o tamanho médio dos domicílios varia mais fortemente e onde é maior o percentual de população acima de 59 anos e os domicílios unipessoais. Essa associação pôde se dar em função de não havermos feito corte de idade para os domicílios unipessoais. Neste grupo pode haver, portanto, pessoas na faixa etária "60 anos e mais" residindo sós, o que não é incomum considerando-se aspectos de ciclo de vida do domicílio. Finalmente, notamos que no segundo componente a variável de geração per capita de resíduos não apresenta peso relevante, indicando descolamento entre as características do grupo de áreas que o componente distingue e uma intensa geração per capita de resíduos.

A representação gráfica (component plot) dos indivíduos de análise e das variáveis - como pontos num espaço geométrico formado por eixos dos dois primeiros componentes - fornece uma forma de interpretação amigável dos resultados do método (Figura 1). Os indivíduos, APs no caso, se distribuem conforme sua associação com cada componente, afastando-se do ponto de $[0,0]$ e ocupando os quadrantes do gráfico. Como cada ponto interage com ambos os eixos, a distribuição se dá como se houvesse uma interação gravitacional entre eixos e pontos: todos estes se afastam do ponto origem em direção aos extremos de cada eixo, como função do valor específico por variável para cada caso/ponto/indivíduo. Desta forma, acima e abaixo do eixo horizontal do component plot se localizam os pontos que se relacionam de forma positiva e negativa respectivamente com o primeiro componente, o mesmo valendo para o segundo, desta vez à direita e à esquerda.

Observa-se que o vetor associado à variável geração per capita de resíduos se comporta de forma muito similar ao grupo das variáveis socioeconômicas e ao grupo domicílios unipessoais, domicílios sem filho e domicílios chefiados por idoso, e idade média da área. Por oposição, a geração per capita é pouco relacionada às áreas com domicílios extensos (acima de três filhos) e áreas de baixa renda.

Vale destacar que as variáveis população residente, número de domicílios e taxa de crescimento não apresentam correlação mais estreita com a variável de interesse deste trabalho. Reforça-se a avaliação feita com base nos coeficientes de correlação simples e também a construção teórica da qual esse trabalho partiu.

O método ACP permitiu identificar quais interações acontecem entre os indivíduos e as variáveis. Desejamos, porém, conhecer a formação de grupos de APs, quais características os aproximam internamente e distinguem dos demais grupos e, sobretudo, 
FIGURA 1

Representação gráfica dos componentes 1 e 2 e comportamento dos indivíduos de análises (APs) e variáveis de análise

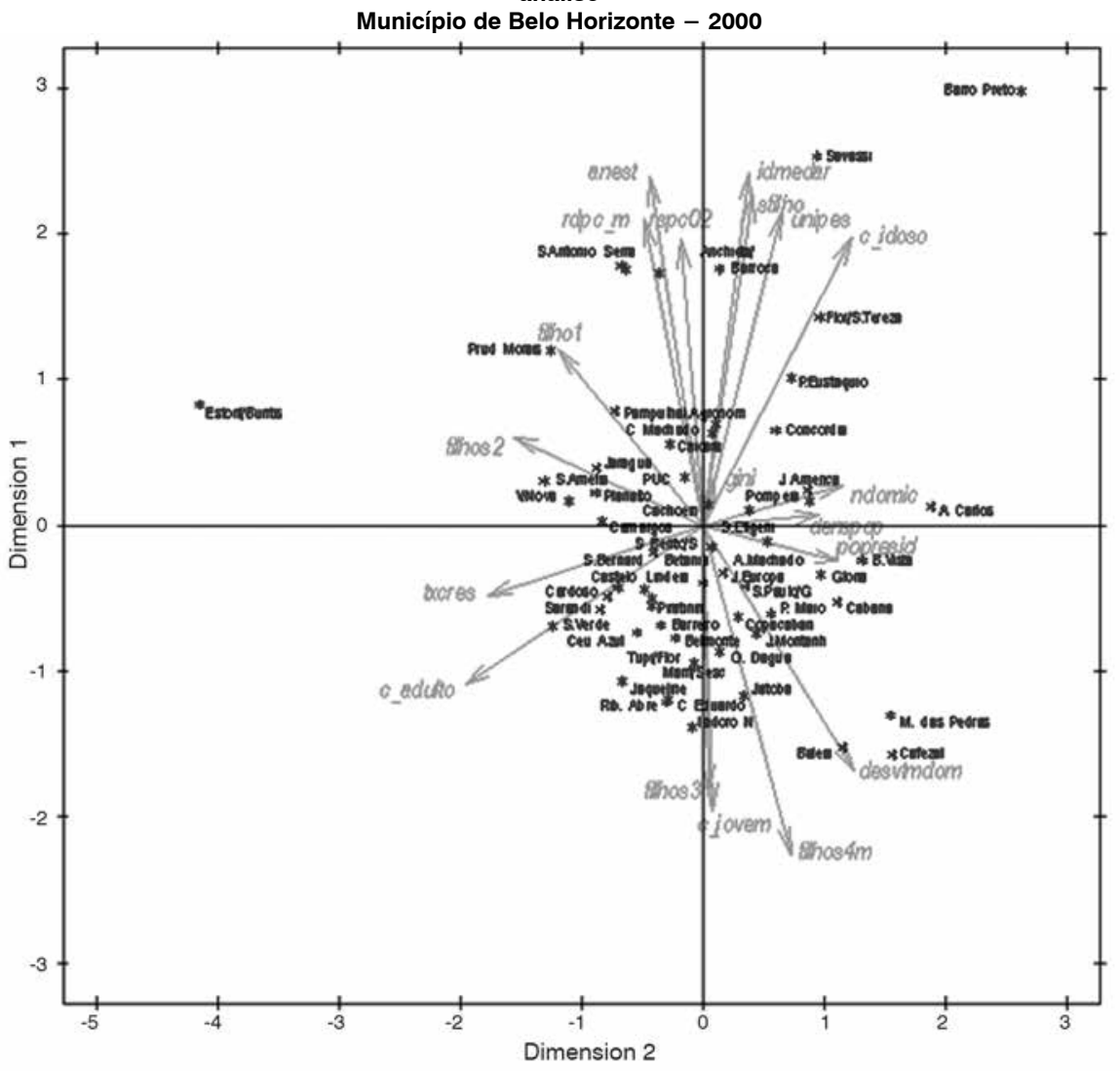

Fonte IBGE. Censo Demográfico; Secretaria Municipal de Limpeza Urbana - SLU 2003. Elaboração própria a partir do pacote estatístico SAS-System.

como se diferencia sua geração domiciliar de resíduos sólidos. Esta avaliação adicional é permitida pelos métodos aglomerativos, ou de clusters, os quais ajudam a aprofundar os resultados até aqui obtidos. Os resultados desta técnica são apresentados a seguir.

\section{Análise de clusters}

A técnica de clusters identifica agrupamentos de indivíduos por meio do cálculo das distâncias entre os pontos que cada um representa num espaço geométrico formado pelas variáveis selecionadas. A escolha das variáveis determina a composição dos agrupamentos. A própria técnica dos com- ponentes principais é uma forma possível de seleção de variáveis se o conjunto inicial parecer extenso ou redundante. Tendo em vista que o método ACP indicou as maiores diferenças entre áreas nos quesitos de renda e educação, por um lado, e as posições extremas da distribuição etária e arranjo domiciliar, por outro, focaremos a análise de agrupamentos nos seguintes conjuntos de variáveis:

- renda domiciliar per capita média (rdpc) e percentual de população no $1^{\circ}$ e $4^{\circ}$ quartis de rdpc (q1rdpc, q4rdpc);

- média de anos de estudo (anest) e população (\%) no $1^{\circ}$ e $4^{\circ}$ quartis de escolaridade (q1anest, q4anest); 
- chefes abaixo de 30 (chjovem) e acima de 60 anos (chidoso);

- domicílios unipessoais (unipes), casais com quatro filhos e mais (qfilemais) e desvio-padrão do tamanho médio do domicílio (desvtd);

- idade média da população (idmedar) e percentual de população abaixo de 15 (pop0_14) e acima de 59 anos (pop60m).

Finalmente, definimos os conglomerados sem a inclusão da variável de geração de resíduos sólidos per capita. Delineados os clusters, os grupos de áreas similares serviram de base para a avaliação da geração de resíduos per capita. O procedimento faz sentido desde que não consideramos razoável que a geração de resíduos seja determinante das características de cada área. Inversamente, se tais características não determinam o padrão de geração dos resíduos, vimos que há associação deste com o perfil socioeconômico e demográfico da área, o que de resto é o pano de fundo último deste trabalho. O Quadro 1 traz a distribuição das áreas de ponderação segundo os clusters definidos pela aplicação do método hierárquico. Identificamos sete grupamentos, aos quais conferimos rótulos de Clusters 1 a Cluster 7.

A distribuição espacial dos conglomerados indica a prevalência dos grupos de alta renda nas regiões centrais ou próximas ao centro, com exceção da Pampulha. 0 Cluster 1 está nas periferias mais externas

QUADRO 1

Distribuição das áreas de ponderação, por clusters de características socioeconômicas e demográficas Município de Belo Horizonte - 2000

\begin{tabular}{|c|c|c|c|c|c|c|c|}
\hline $\begin{array}{l}\text { Número } \\
\text { de APs }\end{array}$ & Cluster 1 & Cluster 2 & Cluster 3 & Cluster 4 & Cluster 5 & Cluster 6 & Cluster 7 \\
\hline 1 & Baleia & Belmonte & Abílio Machado & Camargos & Caiçara & Barro Preto & Anchieta/Sion \\
\hline 2 & Cafezal & Cabana & Antonio Carlos & Concórdia & Castelo & Barroca & $\begin{array}{l}\text { Prudente de } \\
\text { Morais }\end{array}$ \\
\hline 3 & $\begin{array}{l}\text { Capitão } \\
\text { Eduardo }\end{array}$ & Céu Azul & $\begin{array}{l}\text { Barreiro de } \\
\text { Baixo }\end{array}$ & $\begin{array}{l}\text { Jardim } \\
\text { América }\end{array}$ & $\begin{array}{l}\text { Cristiano } \\
\text { Machado }\end{array}$ & $\begin{array}{l}\text { Estoril/ } \\
\text { Buritis }\end{array}$ & Santo Antônio \\
\hline 4 & $\begin{array}{l}\text { Isidoro } \\
\text { Norte }\end{array}$ & Jaqueline & Betânia & Planalto & $\begin{array}{l}\text { Floresta/ } \\
\text { Santa Tereza }\end{array}$ & Pampulha & Savassi \\
\hline 5 & Jatobá & Jardim Europa & Boa Vista & Pompéia & $\begin{array}{l}\text { Instituto } \\
\text { Agronômico }\end{array}$ & $\begin{array}{l}\text { São Bento/ } \\
\text { Sta. Lucia }\end{array}$ & Serra \\
\hline 6 & & $\begin{array}{l}\text { Jardim } \\
\text { Montanhês }\end{array}$ & Cachoeirinha & Santa Efigênia & Jaraguá & & \\
\hline 7 & & Lindéia & Cardoso & & $\begin{array}{l}\text { Padre } \\
\text { Eustáquio }\end{array}$ & & \\
\hline 8 & & $\begin{array}{l}\text { Mantiqueira/ } \\
\text { Sesc }\end{array}$ & Copacabana & & PUC & & \\
\hline 9 & & $\begin{array}{l}\text { Morro das } \\
\text { Pedras }\end{array}$ & Glória & & Santa Amélia & & \\
\hline 10 & & Olhos d' água & São Bernardo & & & & \\
\hline 11 & & Piratininga & Sarandi & & & & \\
\hline 12 & & $\begin{array}{l}\text { Primeiro de } \\
\text { Maio }\end{array}$ & Venda Nova & & & & \\
\hline 13 & & $\begin{array}{l}\text { Ribeiro de } \\
\text { Abreu }\end{array}$ & & & & & \\
\hline 14 & & $\begin{array}{l}\text { São Paulo/ } \\
\text { Goiânia }\end{array}$ & & & & & \\
\hline 15 & & Serra Verde & & & & & \\
\hline 16 & & Tupi/Floramar & & & & & \\
\hline
\end{tabular}

Fonte: IBGE. Censo Demográfico 2000. Elaboração própria (via software Stata). 
ou áreas subnormais. Grupos intermediários ocupam os eixos de expansão da capital de Centro-Sul para Norte (Mapa 2). A distribuição dos indivíduos em conglomerados é melhor se estes são homogêneos internamente. Tendo em vista o teste desta adequação, analisamos médias e desviospadrão internos a cada cluster.

O Cluster 1 é o de RDPC e escolaridade mais baixas entre todos, incluindo os aglomerados (Cafezal e Baleia) e "periferias recentes". Apenas $1,8 \%$ da população estava no quartil mais alto de renda. Mais da metade da população encontrava-se no quartil mais baixo de anos de estudo, com uma média de 1,3 ano. O Cluster 2 é o mais extenso, com 16 áreas, a maioria de renda e escolaridade baixas. Mais de um terço de sua população estava no 10 quartil de renda e somente $3 \%$ no quartil mais alto de escolaridade. O Cluster 3 completa o grupo de RDPC e escolaridade abaixo da média municipal, reunindo áreas que chamaríamos de periferias consolidadas, que incluem re- giões não próximas ao centro, algumas até bastante distantes, economicamente densas, centralidades secundárias na cidade, como Venda Nova e Barreiro de Baixo. De ocupação antiga, sua infraestrutura urbana e condições domiciliares são boas no quadro de referência da cidade e da RMBH. Estes três primeiros clusters têm desvios-padrão baixos - comparados ao município, demais clusters - de renda e escolaridade.

$\mathrm{O}$ quarto e quinto conglomerados formam um grupo intermediário entre os três primeiros, baixas renda e escolaridade, e o grupo oposto nos quais ambas as médias são elevadas. No quarto cluster, áreas do extrato inferior de uma classe média puxam as médias para baixo, enquanto no quinto predominam regiões de classe média alta da capital (Floresta/S. Tereza, PUC, Cristiano Machado).

Os dois últimos clusters reúnem as APs de renda média mais alta da cidade, em geral com áreas integrantes ou contíguas à região Centro-Sul, além da Pampulha. $\mathrm{A}$

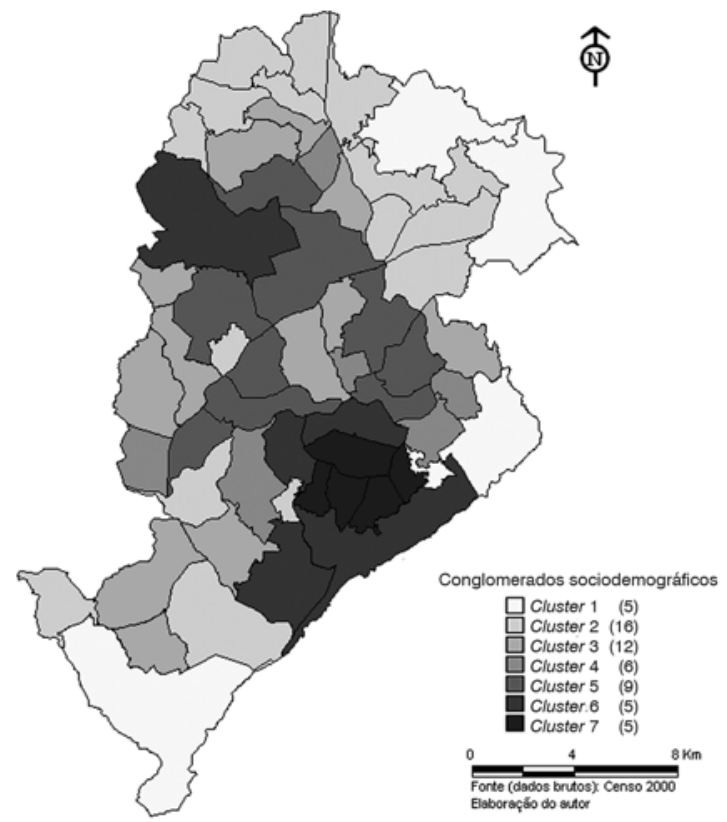

Fonte: IBGE. Censo Demográfico 2000; Secretaria Municipal de Limpeza Urbana - SLU 2003. 
diferenciação deste grupo de "áreas ricas", em dois grupos, deve-se a mais de um fator, nem todos claramente identificáveis. Por um lado, há áreas com médias discrepantes em função de sua diversificação interna. Além disso, o último cluster é formado apenas por áreas integrantes ou contíguas à região Centro-Sul. Não existem, portanto, áreas de ocupação recente, como nos casos de Estoril/Buritis e partes da Pampulha. Ao contrário, todas as APs deste grupo são áreas consolidadas e de alta renda, reforçando tendência de ocupação por domicílios de renda elevada, com exceção das áreas de aglomerados que caem em outros clusters. Este fator socioespacial repercute nas características demográficas locais, reforçando a aderência dos parâmetros demográficos ao esquema traçado na análise de componentes principais: o aumento da renda e escolaridade coincide com áreas de população em idade média mais elevada e menor participação de menores de 15 anos, grupo que decresce cedendo espaço tanto à PIA quanto à população de 60 anos e mais (Tabela 3). O desvio-padrão do tamanho do domicílio apresenta pequena variação, mas também decresce com o aumento da renda. Há, ainda, um alto percentual de domicílios unipessoais e casais sem filhos nos dois clusters mais ricos e escolarizados, o que contrasta com os domicílios mais extensos que convivem em áreas pobres (Tabela 4).
A idade do chefe do domicílio, um marcador do ciclo de vida do domicílio, também se ajusta à tendência: grupos de áreas onde predominam chefes jovens são os de menor renda e escolaridade. A variável que mede o percentual de chefes do grupo intermediário ( 15 a 59 anos) é a que menos varia entre os conglomerados, embora varie positivamente com o aumento da renda e escolaridade. Repete-se o padrão de áreas centrais relativamente ricas em oposição às periferias jovens e pobres.

Uma observação importante é a respeito da produção relativa de resíduos entre os clusters (Tabela 5). Tomando o Cluster 1, o mais jovem e de renda mais baixa, como parâmetro, verifica-se que as produções de resíduos dos Clusters 6 e 7 representam um nível de geração muito elevado, 210\% e $130 \%$ superiores, respectivamente. Em outros termos, as APs reunidas no cluster onde predomina a renda média mais elevada reúnem uma produção per capita que é igual a três vezes a media do cluster de renda mais baixa. Este não é um resultado trivial, levando-se em conta a participação de toda a cidade no ônus do financiamento do sistema de gestão dos resíduos e a aplicação de um modelo de gestão único para a cidade.

Por fim, avaliou-se a associação entre os clusters socioeconômicos e demográficos e a geração per capita de resíduos. A

TABELA 3

Percentual de domicílios, por grupos etários do chefe, segundo clusters de características socioeconômicas e demográficas

Município de Belo Horizonte - 2000

\begin{tabular}{|c|c|c|c|c|c|c|c|}
\hline \multirow{2}{*}{ Clusters } & \multicolumn{2}{|c|}{ Chefe menor de 30 anos } & \multicolumn{2}{|c|}{ Chefe $30-59$ anos } & \multicolumn{2}{|c|}{ Chefe 60 anos e mais } & \multirow{2}{*}{$\begin{array}{c}\text { Desvio- } \\
\text { padrão } \\
\text { tamanho de } \\
\text { domicílio }\end{array}$} \\
\hline & Média & $\begin{array}{l}\text { Desvio- } \\
\text { padrão }\end{array}$ & Média & $\begin{array}{l}\text { Desvio- } \\
\text { padrão }\end{array}$ & Média & $\begin{array}{l}\text { Desvio- } \\
\text { padrão }\end{array}$ & \\
\hline Cluster 1 & 20,0 & 1,9 & 67,4 & 1,9 & 12,7 & 2,1 & 2,1 \\
\hline Cluster 2 & 16,5 & 2,5 & 67,8 & 2,1 & 15,8 & 3,4 & 2,0 \\
\hline Cluster 5 & 10,1 & 2,0 & 67,9 & 4,3 & 22,0 & 5,7 & 1,9 \\
\hline Cluster 6 & 11,1 & 3,9 & 65,4 & 10,5 & 23,5 & 11,5 & 1,8 \\
\hline Cluster 7 & 7,0 & 1,1 & 65,8 & 5,5 & 27,3 & 4,8 & 1,5 \\
\hline
\end{tabular}

Fonte: IBGE. Censo Demográfico 2000; Secretaria Municipal de Limpeza Urbana - SLU 2003. 
TABELA 4

Percentual de domicílios, por arranjos domicílios selecionados, segundo clusters de características socioeconômicas e demográficas Município de Belo Horizonte - 2000

\begin{tabular}{|c|c|c|c|c|c|c|c|c|c|c|c|c|}
\hline \multirow{2}{*}{ Clusters } & \multicolumn{2}{|c|}{$\begin{array}{c}\text { Domicílio } \\
\text { unipessoal }\end{array}$} & \multicolumn{2}{|c|}{$\begin{array}{c}\text { Casais sem } \\
\text { filhos }\end{array}$} & \multicolumn{2}{|c|}{ Um filho } & \multicolumn{2}{|c|}{ Dois filhos } & \multicolumn{2}{|c|}{ Três filhos } & \multicolumn{2}{|c|}{$\begin{array}{c}\text { Quatro filhos e } \\
\text { mais }\end{array}$} \\
\hline & Média & $\begin{array}{l}\text { Desvio- } \\
\text { padrão }\end{array}$ & Média & $\begin{array}{l}\text { Desvio- } \\
\text { padrão }\end{array}$ & Média & $\begin{array}{l}\text { Desvio- } \\
\text { padrão }\end{array}$ & Média & $\begin{array}{l}\text { Desvio- } \\
\text { padrão }\end{array}$ & Média & $\begin{array}{l}\text { Desvio- } \\
\text { padrão }\end{array}$ & Média & $\begin{array}{l}\text { Desvio- } \\
\text { padrão }\end{array}$ \\
\hline Cluster 1 & 8,2 & 1,3 & 8,7 & 0,5 & 17,3 & 1,2 & 26,4 & 2,0 & 23,1 & 1,8 & 24,6 & 4,2 \\
\hline Cluster 2 & 8,5 & 1,4 & 10,5 & 0,9 & 20,1 & 1,9 & 29,7 & 2,1 & 21,6 & 1,2 & 18,2 & 3,8 \\
\hline Cluster 3 & 9,4 & 2,4 & 12,6 & 2,0 & 21,0 & 1,3 & 30,0 & 1,6 & 21,6 & 2,1 & 14,9 & 1,8 \\
\hline Cluster 4 & 12,3 & 2,8 & 15,8 & 2,7 & 21,5 & 2,5 & 29,2 & 1,9 & 20,7 & 2,4 & 12,7 & 2,1 \\
\hline Cluster 5 & 13,9 & 3,8 & 17,9 & 4,2 & 21,5 & 1,8 & 30,9 & 2,0 & 19,1 & 1,8 & 10,6 & 2,9 \\
\hline Cluster 6 & 18,5 & 10,1 & 22,9 & 14,0 & 22,3 & 3,4 & 28,9 & 6,4 & 16,9 & 6,3 & 9,1 & 6,4 \\
\hline Cluster 7 & 18,5 & 4,3 & 23,3 & 4,2 & 21,1 & 2,1 & 33,6 & 2,4 & 17,7 & 1,3 & 4,4 & 1,5 \\
\hline $\begin{array}{l}\text { Belo } \\
\text { Horizonte }\end{array}$ & 3,4 & 2,1 & 14,6 & 6,5 & 20,7 & 2,2 & 29,9 & 3,0 & 20,5 & 2,9 & 14,3 & 6,1 \\
\hline
\end{tabular}

Fonte: IBGE. Censo Demográfico 2000.

TABELA 5

Geração per capita relativa de resíduos, segundo clusters de características socioeconômicas e demográficas Município de Belo Horizonte - 2002

\begin{tabular}{lccc}
\hline & \multicolumn{3}{c}{ Geração per capita (t/ano) } \\
\cline { 2 - 4 } Clusters & Média & Desvio-padrão & $\begin{array}{c}\text { Produção relativa entre } \\
\text { Clusters (Cluster 1 = 100) }\end{array}$ \\
\hline Cluster 1 & 0,156 & 0,081 & 100,0 \\
Cluster 2 & 0,144 & 0,037 & 92,3 \\
Cluster 3 & 0,200 & 0,042 & 128,2 \\
Cluster 4 & 0,223 & 0,039 & 142,9 \\
Cluster 5 & 0,253 & 0,018 & 162,2 \\
Cluster 6 & 0,484 & 0,192 & 310,3 \\
Cluster 7 & 0,361 & 0,134 & 231,4 \\
Belo Horizonte & $\mathbf{0 , 2 3 0}$ & $\mathbf{0 , 1 2 3}$ & $\mathbf{1 4 7 , 2}$
\end{tabular}

Fonte: IBGE. Censo Demográfico 2000; Secretaria Municipal de Limpeza Urbana - SLU 2003.

produção per capita cresce, ainda que não de forma exatamente linear, com o número de ordem dos clusters. Regiões mais ricas, com famílias menores e população menos jovem, geram mais quantidade de resíduo por indivíduo. As curvas dos perfis demográficos mostram comportamento aderente à geração per capita de resíduos, assim como nas curvas de renda e escolaridade, inclusive nos quartis mais altos (Gráficos 5 e 6).

Nota-se que, para o último cluster, há um descolamento entre as curvas, cuja explicação pode passar por fatores não incluídos na análise, como a composição comercial-residencial do conjunto dos imóveis. Outra possível explicação poderia ser encontrada no perfil de consumo das áreas do Cluster 7, vis-à-vis o sexto conglomerado. As áreas do Cluster 7 são as de renda mais alta e que mais se aproximam do perfil urbano-contemporâneo: população na qual é marcante a presença de domicílios unipessoais, casais com menos de dois ou sem filhos, idade média elevada e chefes de domicílios com 60 anos e mais. Em resumo, trata-se de uma população urbana 


\section{GRÁFICO 5}

Renda domiciliar per capita - RDPC (2000), população (\%) no $4^{\circ}$ quartil de RDPC, escolaridade (2000) e geração per capita de resíduos (2002), segundo clusters de características socioeconômicas e demográficas Município de Belo Horizonte
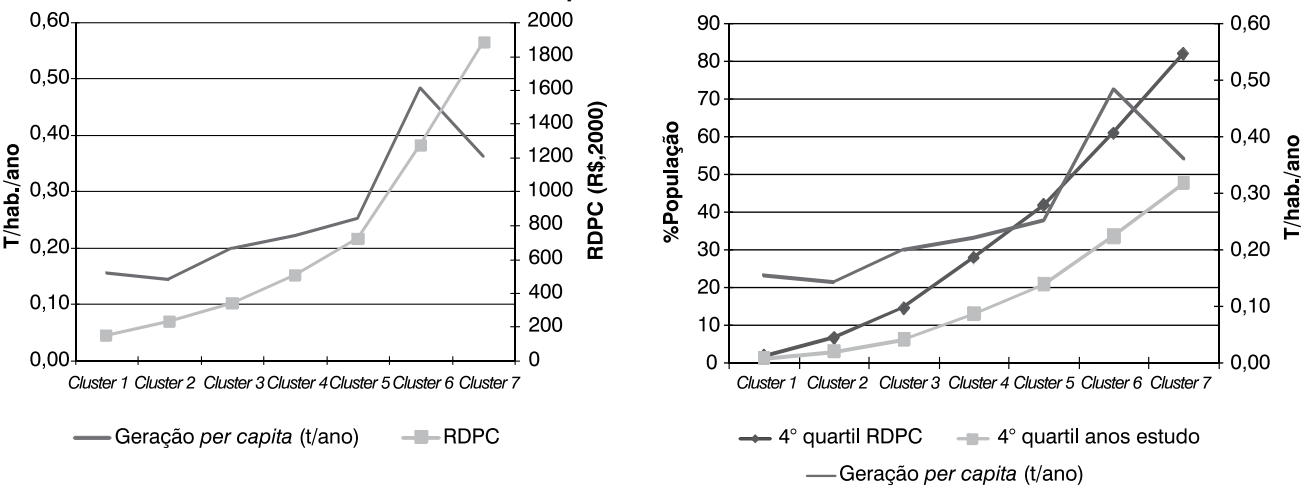

Fonte: IBGE. Censo Demográfico 2000; Secretaria Municipal de Limpeza Urbana - SLU 2003.

GRÁFICO 6

Idade média da população, percentuais de população e chefes de domicílios de 60 e mais, domicílios unipessoais (2000) e geração per capita de resíduos (2002), segundo clusters de características socioeconômicas e demográficas Município de Belo Horizonte
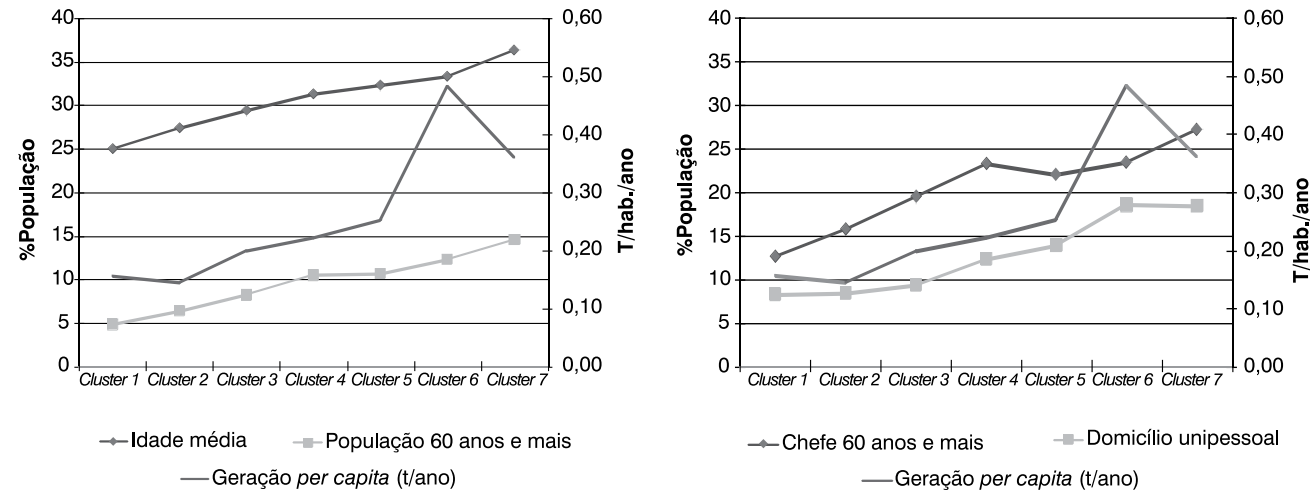

Fonte: IBGE. Censo Demográfico 2000; Secretaria Municipal de Limpeza Urbana - SLU 2003.

em avançado processo de envelhecimento, entrando pela segunda transição demográfica (LESTHAEGHE, 1995).

Embasar este argumento em dados e discuti-lo mais amplamente escapa ao escopo desse trabalho e às possibilidades dos dados disponíveis. Entretanto, alguns estudos defendem que, em um estágio avançado do processo da segunda transição demográfica, a tendência de relação positiva entre intensificação relativa do consumo e aumento da renda começa a se estabilizar e/ou reverter. Isso porque os grupos - ou domicílios - à frente nessa transição tendem a adotar novos conjuntos de preferências e estilos de vida, nos quais existe aumento no consumo de bens não duráveis, configurando um padrão potencializador da geração de resíduos sólidos domiciliares. Este argumento é abordado direta ou indiretamente por Fernández-Villaverde e Krueger (2001), Surkiyn e Lesthaeghe (2004), Rose e Villeneuve (2005), entre outros.

A aplicabilidade deste argumento ao caso brasileiro e do município de Belo Horizonte, em particular, significa, em parte, rediscutir o argumento central deste trabalho - isto é, há uma cadeia de autorreforço entre 
renda, consumo e geração de resíduos. No entanto, como em outros processos sociais, não se trata de um cenário de alternativas excludentes, ou esta ou aquela. Os fenômenos sociais são mediatos e processuais, isto é, admitem estágios e fases que se superpõem no tempo e no espaço.

\section{Considerações finais}

A busca de novas fontes de dados para a pesquisa em população e meio ambiente tem valor intrínseco. A área é uma das que mais se ressentem de informações confiáveis e passíveis de uso em conjunção com dados censitários. Iniciativas de investigação em fontes alternativas de dados, providos por instituições públicas ou privadas, constituem um potencial ainda não muito explorado para fins de pesquisa, o que, no final do processo de geração de conhecimento, reverte-se em insumo a própria ação do agente público. Este trabalho, aplicando de forma inédita os dados produzidos pela administração pública da capital do Estado de Minas Gerais, vem como contribuição a esse quadro, na medida em que reúne um arcabouço conceitual e uma proposta implícita de intensificação do uso de dados produzidos por agências públicas sobre questões urbano-ambientais, o que constitui um instrumento para o desenho de políticas no setor.

A hipótese de trabalho empregada é que diferenciais demográficos e socioeconômicos se expressam em um padrão diferenciado de geração de resíduos per capita e também de composição do resíduo gerado, por via de uma relação entre espaço urbano, consumo, renda e estrutura etária. Os resultados deste trabalho corroboram essa hipótese. No município de Belo Horizonte, diferenciais demográficos em termos

\section{Referências}

ALVES, J. E. D. As características dos domicílios brasileiros entre 1960 e 2000. Rio de Janeiro: Escola Nacional de Ciências Estatísticas, 2004. Disponível em: <http:// www.ence.ibge.gov.br/publicacoes/>. Acesso em: 26 out. 2009. de estrutura etária e domiciliar, assim como renda e escolaridade, são fatores codeterminantes da quantidade e composição dos resíduos sólidos domiciliares.

A análise realizada mostrou que a concentração de domicílios unipessoais, de população e chefes com 60 anos e mais, e idade média elevada, algo que rotulamos "perfil demográfico urbano-contemporâneo", surge recorrentemente como fator demográfico central na diferenciação de áreas de maior geração de resíduos per capita. Estes fatores vêm associados constantemente à renda e escolaridade elevadas. À medida que este perfil de população se difunde e ao mesmo tempo se concentra em áreas específicas das cidades, seu consumo altamente orientado para o mercado, inclusive de alimentação industrializada, pode implicar aumento relativo de resíduos recicláveis.

Um aspecto notável é que o tamanho da população residente por área não surgiu como fator determinante em nenhuma etapa da análise. A taxa de crescimento da população segundo área surge como aspecto importante, mas distintivo de áreas em expansão recente, quase sempre periferias com população de baixa renda, logo, regiões onde a produção per capita de resíduos é menor. Essa associação não tem, portanto, o sentido límpido que parece ter quando se diz: "cresce a população, crescem os resíduos". Isso depende, de forma importante, de como os fatores socioeconômicos, espaciais e demográficos se relacionam ao padrão de consumo praticado na sociedade. Ainda que se trate de uma primeira abordagem, que como tal se ressente de mais informações e novos estudos, vimos que existem áreas cuja geração per capita de resíduos chega a representar mais que o dobro das áreas periféricas mais pobres.

ÁRIES, F. História social da criança e da família. $2^{\mathrm{a}}$ ed. Rio de Janeiro: Ed. LTC, 1981.

BARBOSA. L. T. Gerenciamento de resíduos sólidos urbanos no norte de Minas Gerais: estudo relativo à implantação de 
unidades de reciclagem e compostagem a partir de 1997. Dissertação (Mestrado), Programa de Pós-Graduação em Saneamento, Meio Ambiente e Recursos Hídricos, Escola de Engenharia - UFMG, 2004.

BARROS, R. P. et al. Acesso ao trabalho e produtividade no Brasil: implicações para crescimento, pobreza e desigualdade. Rio de Janeiro: Ipea, 2004. Disponível em: $<$ http://www.ipea.gov.br>. Acesso em: 15 jan. 2009.

BELO HORIZONTE. Secretaria Municipal de Limpeza Urbana. Relatório geração anual de resíduos 2002. Belo Horizonte, 2003.

Relatório geração anual de resíduos 2005. Belo Horizonte, 2006.

BELO HORIZONTE. Secretaria Municipal de Finanças. Distribuição de imóveis segundo situação comercial e residencial. Belo Horizonte, 2007 (informação interna).

BRASIL. Ministério da Saúde. Datasus. Disponível em: <http://www2.datasus.gov. br>.

BRITO, F.; SOUZA, J. A metropolização da pobreza. In: ENCONTRO NACIONAL DE ESTUDOS POPULACIONAIS, 11. Anais... Belo Horizonte: Abep, 1998.

BUZAR, S.; OGDEN, P. E.; HALL. R. Household matters: the quiet demography of urban transformation. Progress in Human Geography, v. 29, n. 4, 2005. Disponível em: $<$ http://phg.sagepub.com>. Acesso em: 16/ abr. 2007.

CALDERONI, S. Os bilhões perdidos no lixo. São Paulo: Humanitas Editora, 2003.

CALDWELL, J. C. Toward a restatement of demographic transition theory. Population and Development Review, v. 2, n. 3/4, p. 321-366, 1976.

CARVALHO, J. A. M.; SAWYER, D. T. O.; RODRIGUES, R. N. Introdução a alguns conceitos básicos e medidas em demografia. Belo Horizonte: UFMG-Cedeplar, 1998.

CATAPRETA, C.; HELLER, L. Associação entre coleta de resíduos sólidos domiciliares e saúde, Belo Horizonte. Revista Panamericana de Saúde Pública, v. 5, n. 2, 1999.
CHAUÍ, M. Convite à Filosofia. São Paulo: Editora Ática, 2000.

COSTA, A. C. S.; OlIVEIRA, J. G. A.; CORREIA, T. C. V. D. Análise de viabilidade de implementação de um sistema de coleta de lixo auto-sustentável no interior de Minas Gerais. Projeto Final, Curso de Graduação em Engenharia de Produção da UFF, Niterói, 2005. Disponível em: <http:// www.paas.uff.br/textos/proj_final1.pdf $>$. Acesso em: 29 maio 2008.

COSTA, H. S. de M.; MONTE-MÓR, R. L. M. Urbanization \& environment. In: HOGAN; D. J.; BERQUÓ, E.; COSTA, H. S. M. (Orgs.). Population and environment in Brazil. $2^{\text {a }}$ ed. Campinas: CNPD, Abep, Nepo, 2002.

FERNÁNDEZ-VILLAVERDE, J.; KRUEGER, $D$. Consumption and saving over the life cycle: how important are consumer durables? Penn Institute, 2001 (Working papers).

GANZO FERNANDEZ, J. A. C. Ciclo de vida familiar e o projeto de empreendimentos multifamiliares. Tese (Doutorado em Engenharia Civil) - Universidade Federal de Santa Catarina, Florianópolis, 2006.

HAKKERT, R. Fontes de dados demográficos. Belo Horizonte: Abep, 1996.

HARVEY, D. A produção capitalista do espaço. São Paulo: Annablume, 2005.

IBAM - Instituto Brasileiro de Administração Municipal. Manual de gerenciamento Integrado de resíduos sólidos. Rio de Janeiro, 2001.

IBGE - Instituto Brasileiro de Geografia e Estatística. Censo Demográfico 2000. Rio de Janeiro, 2001.

LAM, D. Demographic variables and income inequality. Handbook of population and family economics, volume 1B, cap. 18 , 1997.

The demography of youth in developing countries and its economic implications. World Bank Policy Research W.P. 4022, 2006. Disponível em: <http://www.wds.worldbank.org/servlet/ WDSContentServer/WDSP/IB/2006/10/04/00 
0016406_20061004095006/Rendered/PDF/ wps4022.pdf>. Acesso em: 17 jul. 2007.

LEMOS, C. B.; FERREIRA, G.; HARDY, J.; PEREIRA, M. Questões urbanísticas e socioculturais do município de Belo Horizonte. Projeto BH Século XXI, módulo 2: a questão intra-urbana. Belo Horizonte: Cedeplar-UFMG, 2004. Disponível em: <http://www. cedeplar.ufmg.br/pesquisas/pbh/arquivos/ mod2parte1.pdf>. Acesso em 02 jul. 2008.

LESTHAEGHE, R. Second demographic transition in Western countries. An interpretation. In: MASON, K. O.; JENSEN, A.-M. (Eds.). Gender and family change in industrialized countries. Oxford, England: Clarendon Press, 1995.

LOREK, S. Household energy, water consumption and waste generation: German case study. Viena-Austria: Sustainable Europe Research Institute, 2004 (SERI study, n²).

MARTINE, G. O lugar do espaço na equação população/meio ambiente. Revista Brasileira de Estudos de População, v. 24, n. 2, 2007.

MASON, K. O. Explaining fertility transitions. Demography, v. 37, n. 4, p. 443-454, 1997.

MEDEIROS, M.; OSÓRIO, R. Mudanças nas famílias brasileiras: a composição dos arranjos domiciliares entre 1978 e 1998. Brasília: Ipea, 2002 (Texto para discussão, $\mathrm{n}^{\circ}$ 886). Disponível em: <http://www.ipea. gov.br/pub/td/2002/td_0886.pdf>. Acesso em: 26 out. 2009.

MENDONÇA, J. G.; GODINHO, M. H. L. (Orgs.). População, espaço e gestão na metrópole: novas configurações, velhas desigualdades. 1. ed. Belo Horizonte: PUC Minas, 2003.

MINGOTI, S. Análise de dados através de métodos de estatística multivariada: uma abordagem aplicada. Belo Horizonte: Editora UFMG, 2005.

MONTE-MÓR, R. L. M. Belo Horizonte: a cidade planejada e a metrópole em construção. In: MONTE-MÓR, R. L. M. (Org.). Belo Horizonte: espaços e tempos em construção. Belo Horizonte: Cedeplar/PBH, 1994.
NOTESTEIN, F. Population: the long view. In: SCHULTZ, T.W. Food for the world. Chicago: University of Chicago Press, 1953.

PEBLEY, A. R. Demography and the environment. Demography, v. 35, n. 4, Nov. 1998.

PINHEIRO, C. L. Favelas em Belo Horizonte: de suas origens a uma tipologia atual. Trabalho de Conclusão de Curso (Graduação em Economia) - Universidade Federal de Minas Gerais, Belo Horizonte, 2007.

PRESTON, S. H. Relations between individual life cycles and population characteristics. American Sociological Review, v. 47, n. 2, 1982.

PRINCEN, T. Consumption and environment: some conceptual issues. Ecological Economics, n. 31, 1999. Disponível em: <www.elsevier.com/locate/ecolecon>. Acesso em: 15 fev. 2008.

QUEIROZ, B. L.; TURRA, C. M.; RENTERIA PEREZ, E. The opportunities we cannot forgot: economic consequences of population changes in Brazil. In: XV ENCONTRO NACIONAL DE ESTUDOS POPULACIONAIS. Anais... Caxambu: Abep, 2006. Disponível em: <www.abep.org.br/>. Acesso em: 26 out. 2009.

QUEIROZ, E. Pluriatividade e inserção das famílias rurais no processo de urbanização do rural em Minas Gerais. Dissertação (Mestrado) - Cedeplar/Universidade Federal de Minas Gerais, Belo Horizonte, 2003.

ROSE, D.; VILLENEUVE, P. Life stages, living arrangements and lifestyles: a century of change. In: ANNUAL MEETING OF THE CANADIAN ASSOCIATION OF GEOGRAPHERS, 2005.

SANTOS, M. O espaço dividido: os dois circuitos da economia urbana dos países subdesenvolvidos. São Paulo: Editora da Universidade de São Paulo, 2004.

SARAIVA JR., F. I. Em busca de um modelo brasileiro de ciclo de vida familiar para segmentação de mercado. Dissertação (Mestrado) - Fundação Getulio Vargas/ Escola de Administração de Empresas, São Paulo, 2005. 
SASSEN, S. The global city: New York, London, Tokyo. Princenton: Princenton University, 1991.

SAWYER, D. Population and sustainable consumption in Brazil. In: HOGAN, D. J.; BERQUÓ, E.; COSTA, H. S. M. Population and environment in Brazil. $2^{\mathrm{a}}$ ed. Campinas: CNPD, Abep, Nepo, 2002.

SILVA, H. Aspectos demográficos associados à geração de resíduos sólidos domiciliares no município de Belo Horizonte, 2002. Dissertação (Mestrado em Demografia) - Universidade Federal de Minas Gerais/ Cedeplar, Belo Horizonte, 2008.
SOJA, E. W. Postmetropolis: critical studies of cities and regions. Malden, MA: Blackwell Publishers, 2000.

SURKYN, J.; LESTHAEGHE, R. Value orientations and the second demographic transition in Northern, Western and Southern Europe. Demographic Research, 2004.

TORRES, H. G. SIG e análise sociodemográfica. In: MARQUES, E.; TORRES, H. (Orgs.). São Paulo: segregação, pobreza e desigualdade sociais. São Paulo: Editora Senac, 2005.

\section{Resumen}

Demografía del consumo urbano: un estudio sobre la generación de residuos sólidos domiciliarios en el municipio de Belo Horizonte

Este trabajo explora las relaciones entre factores socioeconómicos y demográficos y la producción de residuos sólidos domiciliarios -la basura doméstica-, en el municipio de Belo Horizonte durante 2002. La propuesta fue investigar si diferenciales socioeconómicos (específicamente, renta y educación) y demográficos (específicamente, estructura etaria y domiciliaria) son importantes en la definición del volumen de residuos generado en sub-regiones del municipio. El consumo, en ese sentido, es visto como el eslabón entre las dimensiones "población" y "generación de residuos". La fuente de datos sobre la generación de residuos sólidos es la Superintendencia de Limpieza Urbana (SLU), responsable de la recogida y sistematización de la información en una red cartográfica digital. Esta representación espacial de la información permitió concatenarla con los datos de la red digital de las Áreas de Ponderación del Instituto Brasileño de Geografía y Estadística (IBGE), referente al Censo Demográfico 2000. Métodos estadísticos multivariados se emplearon para investigar las asociaciones entre variables poblacionales y la producción de residuos. El trabajo destaca en el ámbito de los estudios de población en Brasil, por el uso inédito de información producida sobre residuos sólidos urbanos y la interacción de su producción con aspectos socioeconómicos y demográficos. Los resultados indican que la concentración de domicilios unipersonales, población y jefes con 60 años o más, y una edad media elevada, constituiría algo como un "perfil demográfico urbanocontemporáneo", surge recurrentemente como aspecto demográfico central en la diferenciación de áreas de mayor generación per cápita. Estos factores se asocian constantemente a la renta y escolaridad elevadas.

Palabras-clave: Población. Medio ambiente. Consumo. Residuos sólidos urbanos.

\section{Abstract \\ Demography of urban consumption: a study on the generation of solid waste in the city of Belo Horizonte}

This study explores the relationships between socioeconomic and demographic factors in the production of household solid waste - household trash - in the city of Belo Horizonte in 2002. We propose to investigate whether socioeconomic differentials (particularly income 
and schooling) and demographic differentials (specifically age and household structure) are important in defining the volume of waste generated in the city's subregions. Consumption, in this sense, is seen as the link between the dimensions "population" and "waste generation". The source of data on solid waste generation is the Superintendence of Urban Cleaning (SLU, in Portuguese), responsible for collecting and systematizing information in a digital cartographic grid. This spatial representation of information was concatenated with the data from the digital grid of Enumaration Areas of the Brazilian Institute of Geography and Statistics (IBGE, in Portuguese) for the 2000 Census. Multivariate statistical methods were employed to investigate the associations between population variables and waste production. The work stands out in the Brazilian population studies scenario by its unprecedented use of information on solid waste production and the interaction of socioeconomic and demographic factors. The results indicate that the concentration of single person households, general population and heads of the family aged 60 and over, and high mean age, an "urban-contemporary demographic profile", arises recurrently as demographically central in differentiating areas of higher per capita waste generation. These factors are constantly associated with higher income and schooling.

Keywords: Population. Environment. Consumption. Municipal solid waste.

Recebido para publicação em 13/09/2010 Aceito para publicação em 20/04/2011 
